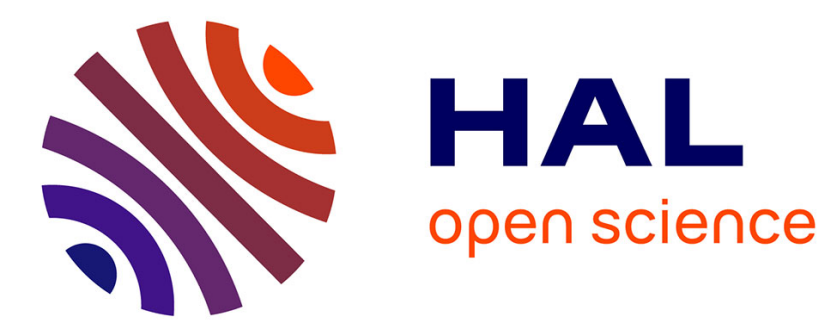

\title{
Cell cycle regulated expression of NCoR might control cyclic expression of androgen responsive genes in an immortalized prostate cell line.
}

\author{
D.M. Altintas, V. Vlaeminck, D. Angelov, S. Dimitrov, J. Samarut
}

\section{- To cite this version:}

D.M. Altintas, V. Vlaeminck, D. Angelov, S. Dimitrov, J. Samarut. Cell cycle regulated expression of NCoR might control cyclic expression of androgen responsive genes in an immortalized prostate cell line.. Molecular and Cellular Endocrinology, 2010, 332 (1-2), pp.149. 10.1016/j.mce.2010.10.007 . hal-00654965

\section{HAL Id: hal-00654965 \\ https://hal.science/hal-00654965}

Submitted on 24 Dec 2011

HAL is a multi-disciplinary open access archive for the deposit and dissemination of scientific research documents, whether they are published or not. The documents may come from teaching and research institutions in France or abroad, or from public or private research centers.
L'archive ouverte pluridisciplinaire HAL, est destinée au dépôt et à la diffusion de documents scientifiques de niveau recherche, publiés ou non, émanant des établissements d'enseignement et de recherche français ou étrangers, des laboratoires publics ou privés. 


\section{Accepted Manuscript}

Title: Cell cycle regulated expression of NCoR might control cyclic expression of androgen responsive genes in an immortalized prostate cell line.

Authors: D.M. Altintas, V. Vlaeminck, D. Angelov, S.

Dimitrov, J. Samarut

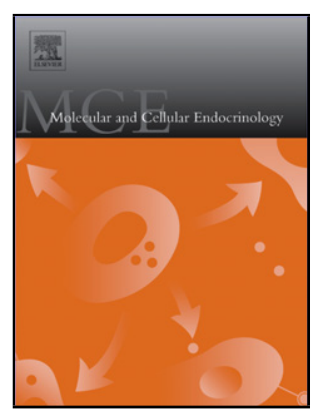

PII: S0303-7207(10)00495-8

DOI: doi:10.1016/j.mce.2010.10.007

Reference: MCE 7655

To appear in: $\quad$ Molecular and Cellular Endocrinology

Received date: $\quad 14-8-2010$

Revised date: $\quad$ 27-9-2010

Accepted date: $\quad 11-10-2010$

Please cite this article as: Altintas, D.M., Vlaeminck, V., Angelov, D., Dimitrov, S., Samarut, J., Cell cycle regulated expression of NCoR might control cyclic expression of androgen responsive genes in an immortalized prostate cell line., Molecular and Cellular Endocrinology (2010), doi:10.1016/j.mce.2010.10.007

This is a PDF file of an unedited manuscript that has been accepted for publication. As a service to our customers we are providing this early version of the manuscript. The manuscript will undergo copyediting, typesetting, and review of the resulting proof before it is published in its final form. Please note that during the production process errors may be discovered which could affect the content, and all legal disclaimers that apply to the journal pertain. 


\section{Cell cycle regulated expression of NCoR might control cyclic expression of androgen responsive genes in an immortalized prostate cell line.}

Altintas D.M. ${ }^{1}$, Vlaeminck V. ${ }^{1,2}$, Angelov D. ${ }^{3}$, Dimitrov S. ${ }^{4}$ and Samarut J. ${ }^{1,2^{*}}$

${ }^{1}$ Institut de Génomique Fonctionnelle de Lyon, Université de Lyon, Université Lyon 1, CNRS,

INRA, Ecole Normale Supérieure de Lyon, Lyon, France

${ }^{2}$ Hospices Civils de Lyon

${ }^{3}$ Laboratoire de Biologie Moléculaire de la Cellule, Université de Lyon, CNRS , Ecole Normale Supérieure de Lyon, Lyon, France

${ }^{4}$ Université Joseph Fourier - Grenoble 1; INSERM Institut Albert Bonniot U823, Site Santé, BP 170, 38042 Grenoble cedex 9, France

*Corresponding author : Institut de Génomique Fonctionnelle de Lyon, Université de Lyon, Université Lyon 1, CNRS, UMR 5242, INRA, Ecole Normale Supérieure de Lyon, 46, allée d'Italie F-69346 Lyon cedex 07, France. Phone : +33.4.72.72.80.17 Fax : +33.4.72.72.89.92 E-mail : jacques.samarut@ens-lyon.fr 


\section{Abbreviations}

AR: Androgen receptor

ARBS3.12: AR binding site on chromosome 3

ARE: Androgen response element

CBP: calmoduline binding peptide

CDK4: Cyclin dependent kinase 4

ChIP: Chromatin immunoprecipitation

CYR61: Cysteine-rich, angiogenic inducer, 61

DNA: Deoxyribonucleic acid

ELL2: elongation factor, RNA polymerase II

FKBP5: FK506 binding protein 5

GAPDH: Glyceraldehyde 3 phosphate dehydrogenase

HDAC3: Histone deacetylase 3

HPV18: Human papillomavirus 18

mRNA: Messenger ribonucleic acid

NCoR: Nuclear receptor co-repressor

NEP: Neutral endopeptidase

NKX3.1: NK3 homeobox 1

PC: Prostate cancer

SBP: Streptavidine binding peptide

shRNA: Small hairpin RNA

SGK: Serum glucocorticoid kinase

XBP: $\mathrm{X}$ box binding protein 


\begin{abstract}
In this work we have studied the mechanisms of regulation of expression of androgen receptor (AR) target genes. We have used an immortalized non-tumorigenic prostate cell line RWPE$1-\mathrm{AR}^{\mathrm{tag}}$ constitutively expressing an exogenous $\mathrm{AR}$ as a model. We observed that all studied AR target genes exhibited a specific expression during the G1 phase of the cell cycle despite the constitutive expression of AR. Importantly, we found that the expression of NCoR, an AR corepressor, was downregulated during the G1 phase and expressed as mRNA and protein specifically during the S phase. The role of NCoR in repressing androgen-induced expression of AR target genes in $\mathrm{S}$ phase was further demonstrated by altering expression of NCoR during the cell cycle through knock down or induced overexpression. Using two alternative techniques we show that AR binds directly to target DNA in the chromatin only during the G1 phase. These data support the hypothesis that NCoR might control a cell cycle dependent regulation of expression AR target genes in prostate cells.
\end{abstract}

\title{
Keywords
}

Androgen Receptor

NCoR

Chromatin

Gene Expression

Cell Cycle 


\section{Introduction}

Androgen receptor (AR) belongs to the nuclear receptor superfamily. It is a liganddependent transcription factor that directly controls transcription of target genes through the binding to specific Androgen responsive Elements (ARE) within the genome. In men AR is essential for both sexual differentiation and prostate development. On the other hand AR is also implicated in several prostatic diseases including prostate cancer (PC). Prostate cancer is the most common cancer among men in Western countries [1]. Androgens activate cell proliferation at the very early stages of tumor development. The role of $\mathrm{AR}$ in PC development has been widely documented and regulation of AR target genes expression is found deeply altered in many cases of advanced cancer. Androgen suppression therapies can abrogate tumor cell proliferation, however in advanced stages and in metastatic forms of PC, uncontrolled proliferation becomes independent of androgen signaling due to altered AR signaling pathway. In some cases anti-androgen compounds can even activate cell proliferation [2-6]. To explain these phenomena several molecular mechanisms have been proposed including hypersensitivity to androgens due to amplification of genes encoding AR or $\mathrm{AR}$ co-activators, mutations in $\mathrm{AR}$ or co-factors inducing constitutive transcriptional activation of AR target genes, altered cross talks with other signaling pathways. In some cases alterations of AR function results from chromosome rearrangements, etc. [6,7]. Recent studies proposed AR as a licensing factor for DNA replication in prostate cancer cells $[8,9]$. Therefore, it is of crucial importance to understand the molecular mechanisms through which AR regulates target gene transcription in prostate cells and controls thereby cell proliferation.

The activity of nuclear receptors in general, and of AR in particular, is controlled through interaction with co-activators and co-repressors [10]. Co-activators and co-repressors are able to induce alterations in chromatin structure through posttranslational modifications of 
the core histone amino-termini. Among co-repressors NCoR is a high molecular multiprotein complex that comprises seven different subunits. The only identified partner of NCoR that shows an enzymatic (deacetylase) activity is HDAC3 [11]. The mechanisms of action of NCoR were recently reviewed [12].

In this work we aimed at deciphering the mechanisms governing AR accessibility to control regions of target genes in the nucleus and the regulation of AR target gene expression in a model of non-tumor prostate cells. We observed that in these cells AR target genes are expressed only during the G1 phase of the cell cycle in response to androgen stimulation. We show that NCoR is expressed only during the S and G2-M phases of the cell cycle and further demonstrate that this cell cycle dependent expression of NCoR is responsible of the nonproductive binding of $\mathrm{AR}$ to the promoter of target genes during these phases. The interaction of $\mathrm{NCoR}$ and $\mathrm{AR}$ has already been described. However, this interaction was shown to be further stabilized by the treatment with AR antagonists such as bicatulimide or mifepristone $[13,14]$. Our experiments show a new link between AR and NCoR in absence of drug treatment, i.e. in more physiologic conditions. Our data also identify then the cell cycle regulated expression of NCoR as a key factor in the control of cyclic expression of androgen responsive genes.

\section{Materials and Methods}

\subsection{Vectors and cells}

The human cDNA of AR was cloned in the pCTAP vector (Stratagene 240102) to produce an AR tagged on C-terminal by the streptavidin binding peptide (SBP) and the calmodulin binding peptide (CBP). This $\mathrm{AR}^{\mathrm{tag}}$ was cloned into a viral vector, $\mathrm{pWRIR}$, derived from HIV. Construction and production of viral vectors and isolation of infected cells were performed in collaboration with Dr. D. Nègre (vectorology facility, IFR Biosciences Gerland 
Lyon Sud, Lyon, France). In this vector the $\mathrm{AR}^{\text {tag }}$ is transcribed from an internal EF2 promoter. This vector also contains a GFP sequence transcribed from the same EF2 promoter and translated via an IRES sequence. Helper free vector particles were produced trough transfection of the pWRIR-AR DNA into the transcomplementing MCF-7 cells. RWPE-1$\mathrm{AR}^{\mathrm{tag}}$ cells were obtained by infecting RWPE-1 cells with helper free pWRIR-AR particles. The tagging AR did not change its ability to translocate into the nucleus (figure $1 \mathrm{D}$ ). As compared to wtAR the tagged form showed the same functional response curve to increasing concentrations of a reporting ARE construct in transient transfection showing that the transcriptional efficiency was not altered (data not shown). Infection conditions were determined to have no more than 2 particles per cell (multiplicity of infection, MOI=2). GFP positive cells were sorted out by flow cytometry and cloned by single cell seeding into 96-well plates. Cells were maintained in keratinocyte growth medium (Invitrogen 17005-042) supplemented with rEGF (recombinant epithelial growth factor) and BPE (bovine pituary extract) (Invitrogen 37000015), antibiotics and antimycotics. RWPE-1-AR ${ }^{\text {tag }}$ cells were stimulated with $1 \mathrm{nM}$ of R1881, a non-metabolisable androgen, in the growth medium deprived of BPE. R1881 was prepared as an ethanol stock solution and diluted in the growth medium. Non-stimulated cells were treated with diluted ethanol as vehicle.

Human lentiviral NCoR shRNA (036SC-36001V) and Scramble shRNA (036SC108080) particles were bought from TebuBio. MOI was determined using lentiviral copGFP particals (TebuBio 036SC-108084) in RWPE-1-AR ${ }^{\text {tag }}$ cells. Cells were infected with either NCoRs hRNA or Scramble shRNA particles at an MOI=2. Stable clones were selected with puromycin at $1 \mu \mathrm{g} / \mathrm{ml}$ and cells were kept in same antibiotic condition after selection.

To obtain regulated expression of $\mathrm{NCoR}$, we used the pcDNA4/TO plasmid (Invitrogen V1020-20). This plasmid contains a hybrid promoter consisting of the cytomegalovirus immediate-early promoter and two tetracycline operator 2 sites for 
tetracyclin-regulated expression in mammalian cells transfected with the tetracyclin repressor. The plasmid pcDNA4/TONCoR was constructed by transferring the NCoR cDNA from the plasmid pGL3 containing the NCoR cDNA to the pcDNA4/TO plasmid. RWPE-1-AR ${ }^{\text {tag }}$ cells were electroporated first with the pCDNA6/TR vector (Invitrogen V1025-20) for 10 seconds at $250 \mathrm{~V}$ and $500 \mu \mathrm{F}$ (Biorad Gene PulserII). After selection with $5 \mu \mathrm{g} / \mathrm{ml}$ of blasticidin, RWPE-1-AR ${ }^{\text {tag }}$ cells containing the pCDNA6/TR vector were electroporated with either the pCDNA4/TO or the pCDNA4/TONCoR vectors. Each time, shSc vector (Sigma Aldrich Shc002) containing puromycin resistance sequence was added in the electroporation mixture at a ratio 1:10. Cells were selected in keratinocyte medium containing BPE, EGF, $5 \mu \mathrm{g} / \mathrm{ml}$ of blasticidin and $1 \mu \mathrm{g} / \mathrm{ml}$ of puromycin.

\subsection{Cell synchronization and flow cytometry}

Cells were synchronized using a double-thymidine-block protocol [15], with a first block for $24 \mathrm{~h}$, a $9 \mathrm{~h}$ release in presence of $24 \mu \mathrm{M}$ deoxycytosine, and a second block for $20 \mathrm{~h}$. The final concentration of thymidine used in the block medium was $2 \mathrm{mM}$. Cells were treated for $6 \mathrm{~h}$ with $\mathrm{R} 1881$ or ethanol as vehicle at the end of the synchronization process.

The percentage of cells in each phase of the cell cycle was checked by propidium iodide (Invitrogen P1304MP) labeling. The fluorescence was measured by flow cytometry.

To analyze AR translocation in synchronized control and R1881-treated cells, the cells were fixed with paraformaldehyde at the indicated phases of the cell cycle and stained with both Hoechst and anti-AR antibody. The number of AR-positive nuclei was counted in 5 different microscopic fields over 300 cells each.

\subsection{RNA extraction and $q R T-P C R$}

RNA was extracted from cells using Trizol Reagent (MRCGene TR118) following 
manufacturer's instructions. One $\mu \mathrm{g}$ of this RNA was retrotranscribed (Promega M1701). The cDNA obtained was amplified by qPCR using QuantiTect SYBR® Green PCR Kit (Qiagen 204145). Primers used for quantitative PCR were as follows: TBP (Qiagen QS MAX0000721); AR (Qiagen QS MAX0073451); NEP (Qiagen QS MAX0048755); Cyr61 (Qiagen QS MAX0003451); ELL2 (Qiagen QS MAX1666910); SGK1 (Qiagen QS MAX0041293); FKBP5 (Qiagen QS MAX0056714); GAPDH (Qiagen QS MAX1192646); NCoR (Qiagen QS MAX0065541); CDK4 (Qiagen QS MAX0016107).

\subsection{Western Blot}

Cells were lysed during $1 \mathrm{~h}$ in lysis buffer (Tris $\mathrm{HCl}$ pH $7.450 \mathrm{mM}$; $\mathrm{NaCl} 150 \mathrm{mM}$; EDTA $5 \mathrm{mM}$; NP40 $0.5 \% \mathrm{~V} / \mathrm{V}$; DTT $0.1 \mathrm{mM}$ and Roche Complete Protease Inhibitor Cocktail Tablets). After centrifugation at $15000 \mathrm{~g}$ during $10 \mathrm{~min}$ the supernatant was collected and protein concentration determined (Biorad Dc Protein Assay 500-0114). After heat denaturation SDS-PAGE was performed on a $6 \%$ polyacrylamide gel and proteins were transferred to a nitrocellulose membrane (Hybond Amersham Biosciences). Equal loading was checked by Ponceau red staining. The membrane was incubated with a monoclonal anti-AR antibody (Santa Cruz Biotechnology AR (441) sc-7305) and a secondary anti-mouse IgG antibody coupled to peroxidase (Promega anti-mouse IgG HRP W402B). AR was visualized by autoradiography.

\subsection{Chromatin binding analyses by $U V$ induced crosslinking.}

Twenty millions RWPE-1-AR ${ }^{\text {tag }}$ cells were used to perform ChIP experiments. Cells were recovered at each time point following synchronization by scraping in cold PBS. To crosslink protein-DNA complexes, cells were irradiated with a laser as previously described [16]. 
For irradiation of the RWPE-1-AR ${ }^{\text {tag }}$ cells with the UV laser, we have used a specially designed UV laser device that allowed the cells to be irradiated with a single 10 nanoseconds pulse (see supplementary figures S5 A and B for detailed description of the UV laser device and protocol). As expected, no induction of covalent AR-DNA adducts was detected in the control non-irradiated samples (Supplementary figure S5 C).

Cells were kept in cold PBS at a concentration of $2.5 .10^{6} / \mathrm{ml}$ and circulated through laminar flow quartz cell by a peristaltic pump $(2 \mathrm{ml} / \mathrm{min})$ and the crosslinking was performed by irradiating at $0.2 \mathrm{~J} / \mathrm{cm}^{2}$ with the fourth harmonics generation of a Surelite II Nd:YAG laser $(?=266 \mathrm{~nm})$ at a repetition rate of $10 \mathrm{~Hz}$ (see supplementary Figure S5 A and B). The irradiation geometry and parameters were chosen in a way to irradiate each 3.5 ?1 of cell suspension by a single laser pulse. After centrifugation, cell pellets were resuspended in lysis buffer (Hepes 50 mM; EDTA 1mM; NaCl 150 mM; Glycerol 5\%; Triton X-100 1\% and Roche Complete Protease Inhibitor Cocktail Tablets). After 10 minutes of lysis and further centrifugation, nuclei were resuspended in RIPA buffer (Tris pH 810 mM; EDTA $1 \mathrm{mM}$ $\mathrm{NaCl} 150$ mM; Glycerol 5\%; Nadeoxycholate 0.1\%; SDS 0.03\%; Triton X-100 1\% and Roche Complete Protease Inhibitor Cocktail Tablets). Chromatin was shared into small fragments by ultrasounds (Bioruptor, Diagenode) in order to obtain DNA fragments of size between 500 and $1000 \mathrm{bp}$ (not shown). After centrifugation at $15000 \mathrm{~g}$ for 10 minutes, the supernatant was collected and $200 \mu \mathrm{l}$ of SBB 10X (1.5 M KCl; $300 \mathrm{mM}$ Tris; $20 \mathrm{mM}$ EDTA; Triton X-100 $0.1 \%$ ) was added. Forty $\mu 1$ streptavidin Beads (Dynal M-280, Invitrogen 11205D) and blocker mixtures (yeast tRNA $100 \mu \mathrm{g} / \mathrm{ml}$; BSA $200 \mu \mathrm{g} / \mathrm{ml}$ ) were added and let for over-night incubation at $4^{\circ} \mathrm{C}$ with $\mathrm{AR}^{\mathrm{tag}} /$ chromatin complexes. Since the $\mathrm{COOH}$-terminus of $\mathrm{AR}$ was fused to the SBP peptide the AR-DNA complexes were pelleted using magnetic beads coated with streptavidin. The beads were then washed 4 times with SBB containing $300 \mathrm{mM} \mathrm{KCl}, 50$ $\mu \mathrm{g} / \mathrm{ml}$ yeast tRNA and $100 \mu \mathrm{g} / \mathrm{ml} \mathrm{BSA}$ and one time with SBB $150 \mathrm{mM} \mathrm{KCl}$ without any 
blocker. After $3 \mathrm{~h}$ reverse crosslinking at $55^{\circ} \mathrm{C}$ in digestion buffer (Tris pH $810 \mathrm{mM}$; EDTA 1 $\mathrm{mM}$; SDS 0.7\%; Proteinase K $100 \mu \mathrm{g} / \mathrm{ml}$ ), DNA was purified by phenol/chlorophorm extraction. The quantity of DNA was measured by fluorescence (Invitrogen Quantitect Picogreen dsDNA assay Kit P7589).

To ascertain that this cell cycle dependent identification of AR direct binding would not reflect some preferential accessibility of the SBP-peptide tag of AR at G1 phase we performed the same experiment but instead of streptavidin we used anti-AR antibody to immunoprecipitate the covalent AR-DNA complexes. We obtained the same cyclic pattern of binding of the AR, thus excluding any technical artifacts (data not shown).

To recover chromatin-RNA polymerase II complexes, $20.10^{6}$ synchronized RWPE-1$\mathrm{AR}^{\text {tag }}$ cells were processed as for $\mathrm{AR}$ following UV laser crosslinking. Four $\mu \mathrm{g}$ of anti-RNA polymerase II antibody (Upstate CTD4H8) and $40 \mu \mathrm{l}$ of Protein A Magnetic Beads (Invitrogen 10002D) were used to recover protein-DNA complexes. Wash conditions, elution of DNA complexes and DNA analysis were the same as for AR.

\subsection{Chromatin binding analyzes by formaldehyde-induced crosslinking.}

Formaldehyde-induced crosslinking was performed as previously described $[13,17]$.

ReChIP experiment was done as described by [18] with some modifications. Fourty millions synchronized RWPE-1-AR ${ }^{\text {tag }}$ cells were lysed in lysis buffer (Hepes 50 mM; EDTA 1 mM; NaCl 150 mM; Glycerol 5\%; Triton X-100 1\% and Roche Complete Protease Inhibitor Cocktail Tablets). After 10 minutes of lysis and centrifugation, nuclei were resuspended in RIPA buffer (Tris pH 810 mM; EDTA 1 mM NaCl 150 mM; Glycerol 5\%; Nadeoxycholate 0.1\%; SDS 1\%; Triton X-100 1\% and Roche Complete Protease Inhibitor Cocktail Tablets). Chromatin was shared into small fragments by ultrasounds (Bioruptor, Diagenode). Cell lysates were centrifuged for 10 minutes at $4{ }^{\circ} \mathrm{C}$ at $15000 \mathrm{rpm}$. The first immunoprecipitation 
was carried out in the presence of $8 \mu \mathrm{g}$ of anti-NCoR (Santacruz sc-8994) and $80 \mu 1$ of Protein A beads (Invitrogen 10002D). Complexes were washed with RIPA buffer containing $300 \mathrm{mM}$ $\mathrm{NaCl}$ and eluted with $10 \mathrm{mM}$ DTT for 30 minutes at $37^{\circ} \mathrm{C}$. Recovered complexes were diluted 50 times in Re-ChIP buffer (1\% triton X-100; 2 mM EDTA; $150 \mathrm{mM} \mathrm{NaCl} ; 20 \mathrm{mM}$ Tris pH 8). The second immunoprecipitation was performed in presence of $20 \mu \mathrm{g}$ of anti-AR antibody (Upstate PG-21) and $80 \mu \mathrm{l}$ of Protein A beads (Invitrogen 10002D). After 3 washes with ReChIP buffer containing $300 \mathrm{mM} \mathrm{NaCl}$, protein-DNA complexes were de-crosslinked in TE buffer containing $0.7 \%$ SDS and $100 \mu \mathrm{g} / \mathrm{ml}$ of proteinase $\mathrm{K}$ for 4 hours at $55^{\circ} \mathrm{C}$. DNA was purified by phenol/chloroform extraction and analyzed by qPCR after picogreen quantification (Invitrogen Quantitect Picogreen dsDNA assay Kit P7589).

\section{7. qPCR following ChIP and primer sequences.}

For quantitative PCR, $5 \mathrm{ng}$ of input DNA or ChIP DNA were used. The qPCR reactions were performed with different quantities of total DNA. Relative fold changes did not change between different starting DNA quantities, suggesting the linearity of the amplification (data not shown).

The following primers were used:

ARBS3.12 S: GCAGCCTACGAAAGTCCATC

ARBS3.12 AS: ACCCAGAGTTGGAACACAAAG

CYR61 ARE S: TTATCTTCAAGCTGCCTCACC

CYR61 ARE AS: GACTGGCTGAACCTCTTAGGC

ELL2 ARE S: CCCTTGGAGTTAGCCACAAC

ELL2 ARE AS: AATGGAGCAGTGTGCATGAG

FKBP5 ARE S: ACCCTCCCAGGAAGAATTATG 
FKBP ARE AS: CCTTAGATGAGCGGTAGAGAGG

SGK ARE S: AGGGTTTTCAGGTGGGACAGAG

SGK ARE AS: TGAGGAGGTAACAAGCGAAGG

NEP AREII S: TTATGGTGGTTGGGTTTACAC

NEP AREII AS: GGGACAAAATGTCCTGTGC

XBP S: TCTGGAAAGCTCTCGGTTTG

XBP AS: AATCCCTGGCCAAAGGTACT

CDK4 S: ATGCAGACAGGCTGAAAGAC

CDK4 AS: AACTCCCGGCTGAAGGATT

NEP ARE -2 kb S: GGAGTCTCGCTCTGTC

NEP ARE -2 kb AS: GGAGAATGGCTTGAACC

NEP ARE + 2 kb S: CCAATGGCATTCAGTG

NEP ARE + 2 kb AS: CGTAGGAAGGCCTTGAGG

CYR ARE -2 kb S: GGGAGTTAGGAATGCTGG

CYR ARE -2 kb AS: GGGCATCCATATCCC

CYR ARE +2 kb S: CTTACCCCGTCTCCTGC

CYR ARE +2 kb AS: GGGTTGGAAGTCCGAG

\subsection{Flow Cytometry.}

Dual labeling of proteins and DNA on flow cytometry was performed as described previously [9]. For NCoR labeling, 1/50 dilution of polyclonal anti-NCoR antibody was used (Santa Cruz Biotechnology NCoR sc-8994) and for phospho-histone H3 labeling, 1/500 dilution of monoclonal anti-phospho-histone H3 was used (AbCam 14955). Cell pellets were incubated with either FITC conjugated anti-mouse IgG (Jackson 715096151) or anti-rabbit IgG (Jackson 718096152) antibodies. Data were analyzed using a FACSCALIBUR 4C 
Cytometer (Becton Dickinson).

\section{Results}

\subsection{Establishment of a stable RWPE-1 prostate cell line expressing AR.}

The aim of this work was to investigate the molecular mechanisms of the control of expression of AR target genes in prostate cells. Several tumor-derived adult prostatic epithelial cell lines (including $\mathrm{LNCaP}, \mathrm{VCaP}$ and $\mathrm{LAPC}-4$ ) have been established and described in the literature [19]. Although most of the described cell lines are sensitive to androgens, AR is mutated in many of these cells, and the tumorigenic phenotype of the cells might alter transcriptional response to androgens.

With this in mind we choose the non-tumorigenic immortalized prostate cells RWPE1 as a model. These cells have been immortalized by infection with HPV18 [20]. Like many non-tumorigenic immortalized prostate cells described so far $[17,21,22]$, these cells express barely detectable amounts of AR protein. To overcome this limitation we established a stable cell line RWPE-1-AR ${ }^{\text {tag }}$ that constitutively expresses an exogenous AR. The $\mathrm{COOH}$-terminus of $\mathrm{AR}$ was fused to the SBP and $\mathrm{CBP}$ peptides and the $\mathrm{AR}^{\mathrm{tag}} \mathrm{cDNA}$ sequence was stably introduced into the cell genome via a lentiviral vector to insert a low number of proviral copies. The cell model we established was similar to the one used by Bolton et al. to study binding of AR to chromatin [17].

To analyze the response to androgens in these cells we followed the expression of a panel of known AR target genes. The chosen genes were NEP, CYR61, ELL2, FKBP5 and SGK [17,23-26]. These cells also express the NKX3.1 gene under androgen stimulation but this gene was not included in the panel of studied genes. The nature of the proteins encoded by these genes, and the structure and position of the ARE binding sites within the respective genes are presented in table 1 of supplementary data. 
In contrast to RWPE-1 cells which did not show any enhancement of AR target gene expression upon androgen stimulation, the androgen response in RWPE-1-AR ${ }^{\text {tag }}$ cells was detected as soon as 3 hours after addition of R1881 with for some of the genes a particularly high transcriptional activation (>10, data not shown).

\subsection{Cell-cycle-dependent Expression of AR Target Genes in RWPE-1-AR ${ }^{\text {tag }}$ Cells.}

To investigate the response to androgens during the cell cycle, we performed a cell cycle synchronization of the RWPE-1-AR ${ }^{\text {tag }}$ cells using the double thymidine block technique [15]. The protocol scheme is presented in Figure 1A. At each step of the synchronization procedure the percentage of cells at the different phases of the cycle was assessed by FACS analysis. The data showed that the double thymidine block resulted in a highly efficient synchronization of the RWPE-1-AR ${ }^{\text {tag }}$ cells. Indeed, more than $60 \%$ of the cells were in S phase at point $\mathrm{T} 0$, close to $70 \%$ in $\mathrm{G} 2 / \mathrm{M}$ at time $\mathrm{T} 1$ and more than $80 \%$ in $\mathrm{G} 1$ at time $\mathrm{T} 2$ (Figure 1 B). After refeeding with normal medium at time T3, the cells entered into a second cell cycle. Six hours after refeeding (time T4), $40 \%$ of the cells were in both S and G1 phases and after 26 hours (time T5) more than $80 \%$ of cells reached again the G1 phase (Figure $1 \mathrm{~B}$ ). Treatment with $1 \mathrm{nM}$ of R1881 for 6 hours had no effect on the synchronization of the cells (data not shown). For simplicity we will further refer T0, T1, T2, T4 and T5 to as Smax, G2/Mmax, G1max, G1/S and G1max-2, respectively.

A Western blot analysis showed that the level of expression of AR was constant during the cell cycle (Figure $1 \mathrm{C}$ ). We also found that the translocation of AR into the nucleus was strongly enhanced by androgen stimulation and that the level of the translocated AR remained unchanged at the different phases of the cell cycle (Figure 1 D). Thus, this synchronization procedure of the RWPE-1-AR ${ }^{\text {tag }}$ cells offered a good model to study how ARtarget gene expression is regulated during the cell cycle. The light bands observed under the 
major band for AR might represent minor cleavage or degradation products.

Analysis of the expression of AR-target genes in response to R1881 in synchronized cells showed that all studied target genes exhibited a cell cycle dependent expression which peaked at the G1 phase (Figure 2). As controls we analyzed the expression of the non ARtarget genes GAPDH and CDK4. As expected, the mRNA levels of these genes did not change significantly during the cell cycle in response to R1881. Similarly, the level of AR mRNA did not vary during the cycle since AR was constitutively expressed from the retroviral vector. We conclude that in response to androgen stimulation the expression of ARtarget genes (as assessed by their mRNA levels) takes place mainly in the G1 phase of the cell cycle.

\subsection{Cell cycle dependent expression of NCoR in RWPE-1-AR ${ }^{\text {tag }}$ cells}

The transcriptional activity of AR is regulated through interactions with co-activator and co-repressor partner proteins [27]. We hypothesized that the cyclic expression of ARtarget genes might be regulated through cell cycle dependent expression and/or activity of such partners. Through screening several AR co-factors for their expression in synchronized cells by RT-qPCR we found that the co-repressor NCoR exhibited an interesting pattern of expression. Its mRNA level was high in $\mathrm{S}$ and $\mathrm{G} 2 / \mathrm{M}$ phases and showed a sharp decrease in G1 (Figure 3 A). In agreement with this finding, the protein was detected predominantly during the $\mathrm{S}$ phase and at a much lower but still detectable level during the $\mathrm{G} 2 / \mathrm{M}$ phase (Figure 3 B).

We further demonstrated that this $\mathrm{S}$ phase specific NCoR expression was not an artifact induced by the synchronization procedure by analyzing the expression of NCoR in non-synchronized cells by FACS. As a control we have studied the cell cycle dependent phosphorylation of histone $\mathrm{H} 3$. Histone $\mathrm{H} 3$ is phosphorylated at the $\mathrm{G} 2 / \mathrm{M}$ phase and, as 
mitosis proceeds, it is dephosphorylated at anaphase [28]. From the FACS analysis presented in figure $3 \mathrm{C}$ and supplementary data S2 we estimated that close to $73 \%$ of cells in S phase were positive for NCoR. In the G1 phase the fraction of NCoR positive cells represented less than $10 \%$. R1881 treatment did not alter this expression pattern (data not shown). This pattern of expression was not specific to the modified RWPE-1-AR ${ }^{\text {tag }}$ cells. Indeed the original RWPE-1 cells as well as their Ki-ras-transformed malignant counterpart RWPE-2 (14) showed the same preferential expression of NCoR during the $S$ and G2/M phases (supplementary figure S1). Furthermore, we also found that this cell cycle dependent expression of NCoR is preserved in other prostate cell lines (supplementary data S2). Indeed, in PC3 and LNCaP cells, a major expression of NCoR was observed in cells in S phase. These data clearly demonstrate that cell cycle dependent expression of $\mathrm{NCoR}$ is not restricted to the RWPE-1 cellular model.

Taken together, all these data demonstrate that NCoR expression is regulated during the cell cycle and peaks at the $\mathrm{S}$ and early $\mathrm{G} 2 / \mathrm{M}$ phases.

\subsection{NCoR binds to chromatin only during the S Phase of the cell cycle.}

The above data suggest that the cyclic expression of NCoR could be associated with the regulation of the expression of AR target genes during the cell cycle. To test this assumption we have analyzed the NCoR binding pattern to the chromatin of AR-target genes during the cell cycle using formaldehyde-induced crosslinking followed by chromatin immunoprecipitation (ChIP). As seen in Figure 4, NCoR was associated with the ARE in the chromatin of all tested AR-target genes only during the $\mathrm{S}$ phase in both the presence and absence of R1881. Surprisingly when tested on the CYR61 and NEP genes, NCoR was also found associated with sites located $2 \mathrm{~kb}$ upstream and downstream from the ARE. No NCoR 
association was found on the androgen-independent XBP gene.

\subsection{Analysis of AR binding to AR-target genes within the chromatin}

AR was constitutively expressed all along the cell cycle in RWPE-1-AR ${ }^{\text {tag }}$ cells (Figure 1). Bearing this in mind, we next asked whether AR was also constitutively bound to its target genes throughout the cell cycle and if bound, whether its binding is productive in term of transcription. To address this question we used two different crosslinking techniques, namely formaldehyde and UV laser protein-DNA crosslinking that distinguish between direct and indirect binding to chromatin DNA.

The widely used formaldehyde crosslinking technique reveals protein binding to chromatin DNA either as a direct interaction with DNA or as an indirect interaction though protein-protein induced crosslinking [29]. In contrast the UV laser induced crosslinking technique reveals only direct protein-DNA interactions. Indeed one of the most efficient photoreaction induced by UV laser irradiation of nucleoprotein complexes is the generation of covalent protein-DNA adducts [30]. Since UV light is a "zero length crosslinking agent" the protein-DNA crosslinking is achieved only between the DNA bases and the amino acids residues that are in direct contact [30] . In addition, no protein-protein crosslink is induced in these conditions $[16,31,32]$. The UV laser crosslinking technique was successfully applied to study the direct binding of histone and several transcription factors to DNA both in vitro and in vivo [33-38] and to map transcription factor-DNA contact points [39].

Using the formaldehyde-induced crosslinking we then analyzed the interaction of AR with the ARE of NEP, CYR61, FKBP5, ELL2, ARBS3.12 and SGK genes. We also analyzed binding to sequences located $2 \mathrm{~kb}$ upstream and downstream from the ARE of NEP and CYR61. The promoter regions of XBP and CDK4 genes that are not AR-targets were used as negative controls. The analysis was conducted at various phases of the cell cycle on 
synchronized RWPE-1-AR ${ }^{\text {tag }}$ cells. All the data are presented in figure 5. Upon R1881 treatment a very high enrichment of AR associated with the ARE of all analyzed AR-target genes was found mostly at the G1 and S phases. A much lower, but still significant binding, was found at the G2/M phase. No AR binding to the chromatin of CDK4 and XBP genes was detected at any phase of the cell cycle. These data illustrate that in RWPE-1-AR ${ }^{\text {tag }}$ cells AR is associated with the ARE during both G1 and S phase. No significant interaction of AR with the chromatin was observed $2 \mathrm{~kb}$ outside of the ARE on the NEP and CYR61 genes.

Using the UV laser crosslinking technique we could observe that the direct binding of AR was clearly enhanced by androgen stimulation and took place mainly at the G1 phase on the ARE of all AR-target genes (Figure 6). A lower binding in the G1/S phase might reflect a smaller fraction of cells in G1 in these samples. As expected, AR did not bind to regions located $2 \mathrm{~Kb}$ down and upstream from the respective ARE sequences of the two genes Cyr61 and NEP. No binding of AR was detected on the non-AR target genes CDK4 and XBP.

From all these observations we conclude that the direct binding of AR to its cognate sequences occurs mostly during the G1 phase whereas indirect binding to the same sites could also take place during the $\mathrm{S}$ phase.

\subsection{Direct G1 phase binding of AR correlates with the transcriptional activation of its target genes}

To test whether AR binding in G1 takes place on transcriptionally active target genes we analyzed the direct binding of RNA polymerase II using the UV laser-crosslinking technique. As shown in Figure 7, in the presence of androgens, RNA polymerase II was found directly bound to the ARE of all tested AR target genes only in G1. On the CDK4 gene (whose expression is independent of the cell cycle) RNA polymerase II was found to bind to the promoter region independently of androgen stimulation and nearly at the same level at 
each phase of the cell cycle. As expected no binding of RNA polymerase II was detected on the non-induced XBP gene. Therefore, these data demonstrate a strong correlation between direct binding of AR and RNA polymerase II to the control regions of AR-target genes during the G1 phase of the cell cycle and the specific expression of these genes during this phase.

\subsection{NCoR interacts with AR on ARE during the $S$ phase of the cell cycle.}

To further characterize cell cycle dependent regulation of AR by NCoR, a sequential ChIP experiment was performed to analyze the interaction between NCoR and AR during the cell cycle. The first immunoprecipitation was carried out using an anti-NCoR antibody. The eluted material was next immunoprecipitated with an anti-AR antibody. As shown in Figure 8 AR and NCoR interacted to each other on the ARE of the tested NEP, CYR61 and FKBP5 genes in the presence of R1881 during the S phase. Note that no interaction of NCoR and AR was detected $2 \mathrm{~kb}$ outside of ARE. Identical results were obtained when the order of the two immunoprecipitations was inverted (Supplementary Figure S3). These data showed that in S phase NCoR and AR interact between each other and with the DNA in the chromatin of ARtarget genes.

\subsection{Alterations of the cell cycle NCoR expression affect the cyclic expression of AR target genes.}

To confirm that NCoR could be involved in the cell cycle regulation of AR-target genes we stably knocked it down using virally expressed specific NCoR-shRNA. The effects were analyzed in synchronized cells. In NCoR-shRNA-infected RWPE-1-AR ${ }^{\text {tag }}$ cells the level of NCoR mRNA was reduced by $65 \%$ and the level of the protein was undetectable (Figure 9 A).

Data presented in Figure $9 \mathrm{~B}$ show that in the presence of R1881 NCoR-shRNA 
induced a re-expression of the NEP, SGK and FKBP5 genes during the $\mathrm{S}$ phase in addition to the expression during the G1 phase. The knockdown of NCoR had only a marginal effect on the expression level of CDK4, GAPDH and AR genes. Similar data were obtained in cells transfected with NCoR-siRNA (supplementary figure S4). These data strongly suggest that NCoR is involved in the down regulation of AR-target genes during the $\mathrm{S}$ phase.

To check whether this re-expression in $\mathrm{S}$ phase did indeed correlate with the direct binding of AR to the target ARE, we analyzed the binding of AR on the NEP, SGK and FKBP5 ARE using the UV Laser crosslinking technique. As shown in Figure $9 \mathrm{C}$ the downregulation of NCoR was associated with a direct binding of AR to the ARE during both the S and G1 phases. No change in S phase was observed for the control genes CDK4 and GAPDH (not shown).

To further confirm the role of NCoR in the cell cycle expression of AR target genes, we used an alternative strategy allowing the permanent expression of the protein during the cell cycle. We first established an RWPE-1-AR ${ }^{\text {tag }}$ cell lines containing a stably integrated NCoR gene under the control of the doxycycline (Dox) inducible promoter (RWPE-1-AR ${ }^{\text {tag }}$ TONCoR cell line). As shown in Figure 10 A, upon Dox treatment NCoR mRNA and protein levels were up regulated $\sim 2$ fold in both the G1 and S phases as compared to non-treated cells (or cell containing an empty vector, data not shown). As shown in figure $10 \mathrm{~B}$ the treatment with Dox affected slightly the expression of AR and had, as expected, no effect on the expression of the CDK4 gene. In contrast the expression of the tested AR-target genes NEP and CYR61 was abrogated during the G1 phase.

Taken altogether these data identify NCoR as the major actor restricting activation of the expression of AR-target genes specifically to the G1 phase in the RWPE-1-AR ${ }^{\text {tag }}$ cells. 


\section{Discussion}

The aim of this work was to investigate the pattern of expression of AR-target genes in a prostate immortalized cell line carrying a constitutively expressed exogenous AR. We found that in these cells, androgen-induced expression of AR-target genes assessed from mRNA expression took place only during the G1 phase of the cell cycle. Searching factors that might control a cell cycle specific regulation of transcription we found that the co-repressor NCoR was expressed specifically during the $\mathrm{S}$ and early $\mathrm{G} 2 / \mathrm{M}$ phases. This has led us to carry out experiments which demonstrated that NCoR should be involved in the G1 phase specific expression of AR-target genes. Indeed, down-regulation of NCoR expression by shRNA or siRNA resulted in a re-expression of AR-target genes in S phase (where they are otherwise silent). In contrast, the constitutive expression of NCoR during the cell cycle induced a repression of AR-target genes expression during the G1 phase.

Another original finding of this work was brought from the use of two alternative techniques to study the binding of these proteins to chromatin DNA, namely formaldehydeand UV laser-crosslinking techniques. The widely-used formaldehyde crosslinking technique induces protein-protein as well as protein-DNA covalent crosslinking and thus reveals both direct and indirect binding of proteins to DNA [29]. The UV laser-induced crosslinking technique induces only protein-DNA crosslinking and thus reflects exclusively direct protein binding to chromatin DNA $[16,32,40]$.

The quantities of the total DNA recovered from ChIP performed after respectively formaldehyde- or UV laser-induced crosslinking were comparable (data not shown). However, both techniques induced different enrichments of complexed chromatin. This difference was probably due to the lower efficiency of crosslinking induced by UV laser irradiation as compared to formaldehyde. Noteworthy, under the conditions of UV irradiation roughly 6-8\% of the histones are found covalently crosslinked to DNA [38]. Alternatively the 
higher enrichment of bound chromatin after formaldehyde-induced crosslinking might reflect the consequences of indirect binding through protein-protein interactions [41].

By using these two techniques we have demonstrated that: (i) AR bound directly to target gene DNA only at G1 phase and, (ii) AR appeared to bind indirectly to chromatin during S phase of the cell cycle. Noteworthy, the binding at G1 correlated with the direct binding of polymerase II to target genes exclusively during this phase which strongly suggests that in G1 expression of AR target genes resulted from AR induced transcriptional activation through a direct and productive interaction with the DNA of the control regions of these genes.

We have also observed a decrease of the expression of AR-target genes during the G2/M transition. This correlated with a strong decrease of the interaction of $A R$ and polymerase II with the AR target gene chromatin. As the amount of expressed exogenous AR was constant during the cell cycle the above effect should reflect the release of AR from the chromatin during the G2/M phase. Such release was also described for several other transcription factors and appeared to be associated with chromatin condensation during mitosis [42].

The formaldehyde-crosslinking technique showed that $\mathrm{NCoR}$ protein bound to AR target genes only during the S phase. As no binding was detected following the UV laser crosslinking technique (not shown) we conclude that NCoR bound to the chromatin of ARtarget genes in $\mathrm{S}$ phase through protein-protein and not direct protein-DNA interactions. NCoR was found to bind also to the chromatin regions located $2 \mathrm{~kb}$ around the ARE which strongly suggests that binding of NCoR to AR-target genes in not governed by the presence of the ARE. We assume that in order to act as a repressor, NCoR has to "coat" relatively large chromatin fragments. This raises the question of how NCoR recognizes and coats the promoter and surrounding chromatin regions. We cannot give a definitive answer to this 
question, but we can hypothesize that other, yet not identified factors, different from AR, might "guide" NCoR over the AR-target genes.

We have also found that when abrogating expression of NCoR during the S phase in shRNA expressing cells, AR can bind again directly and productively to ARE. This suggests that the binding of $\mathrm{NCoR}$ to the chromatin in $\mathrm{S}$ phase interferes with the direct interaction of AR with ARE DNA. We speculate that the constitutive expression of an exogenous AR leads to its permanent interaction with the chromatin during the whole cell cycle. In S phase NCoR binds to AR and displaces it from its direct interaction to the ARE DNA. In the absence of NCoR in G1 phase, AR is again able to directly interact with DNA and to drive transcriptional activation.

We note that this mechanism of regulation would operate in our experimental system, i.e. in the prostate cell line which constitutively expressed AR. Such mechanism may not, however, operate, in genetically non-modified or other prostate cell lines, since in such cell lines AR is not expressed during the whole cell cycle. For example, in prostate tumor cell lines, Litvinov et al. showed that endogenous AR is ubiquitinylated and degraded during the M phase [9]. The question remains to know whether this cell cycle regulation of AR target genes by androgens would exist in prostate cancer cells expressing an endogenous AR. We could not address this question because we have been unable to perform a reliable and repetitive synchronization of tumor prostate cell lines using the thymidine block protocol used here. This defect might be due to the tumor nature of the cells which there from exhibit a completely deregulated cell cycle control. Nonetheless, the RWPE-1-AR ${ }^{\text {tag }}$ cell line we developed was very useful to identify a cell cycle regulated expression of NCoR and to dissect the potential role of $\mathrm{NCoR}$ in the regulation of expression of $\mathrm{AR}$ target genes. In this context, it is worthwhile to stress that NCoR appears to regulate the cell cycle expression of AR target genes even in the large excess of AR. It is interesting to notice that although the mRNA of 
NCoR was still detectable during the G2/M phase its protein amount was globally deeply decreased. FACS distribution of NCoR positive cells showed that this decrease was even more pronounced in cells in late $\mathrm{G} 2 / \mathrm{M}$ phase. This might suggest that NCoR protein expression might follow a specific post-transcriptional regulation during late G2/M phase.

In conclusion these data open thus new considerations on the roles and mechanisms of action of NCoR in prostate cells. 


\section{Acknowledgments}

We thank A. Yurdusev, for technical assistance in cloning NCoR and screening AR cofactors during the cell cycle. This work was supported by Ligue Nationale Contre le Cancer as a grant for Equipe Labelisée. 


\section{References:}

[1] Jemal, A., Siegel, R., Ward, E., Murray, T., Xu, J. and Thun, M.J. (2007) Cancer statistics, 2007. CA Cancer J Clin 57, 43-66.

[2] Balk, S.P. and Knudsen, K.E. (2008) AR, the cell cycle, and prostate cancer. Nucl Recept Signal 6, e001.

[3] Foradori, C.D., Weiser, M.J. and Handa, R.J. (2008) Non-genomic actions of androgens. Front Neuroendocrinol 29, 169-81.

[4] Heinlein, C.A. and Chang, C. (2004) Androgen receptor in prostate cancer. Endocr Rev 25, 276-308.

[5] Nelson, W.G., De Marzo, A.M. and Isaacs, W.B. (2003) Prostate cancer. N Engl J Med 349, 366-81.

[6] Feldman, B.J. and Feldman, D. (2001) The development of androgen-independent prostate cancer. Nat Rev Cancer 1, 34-45.

[7] Narod, S.A., Seth, A. and Nam, R. (2008) Fusion in the ETS gene family and prostate cancer. Br J Cancer 99, 847-51.

[8] D'Antonio, J.M., Vander Griend, D.J. and Isaacs, J.T. (2009) DNA licensing as a novel androgen receptor mediated therapeutic target for prostate cancer. Endocr Relat Cancer 16, 325-32.

[9] Litvinov, I.V., Vander Griend, D.J., Antony, L., Dalrymple, S., De Marzo, A.M., Drake, C.G. and Isaacs, J.T. (2006) Androgen receptor as a licensing factor for DNA replication in androgen-sensitive prostate cancer cells. Proc Natl Acad Sci U S A 103, 15085-90.

[10] Rosenfeld, M.G., Lunyak, V.V. and Glass, C.K. (2006) Sensors and signals: a coactivator/corepressor/epigenetic code for integrating signal-dependent programs of 
transcriptional response. Genes Dev 20, 1405-28.

[11] Karagianni, P. and Wong, J. (2007) HDAC3: taking the SMRT-N-CoRrect road to repression. Oncogene 26, 5439-49.

[12] Perissi, V., Jepsen, K., Glass, C.K. and Rosenfeld, M.G. (2010) Deconstructing repression: evolving models of co-repressor action. Nat Rev Genet 11, 109-23.

[13] Kang, Z., Janne, O.A. and Palvimo, J.J. (2004) Coregulator recruitment and histone modifications in transcriptional regulation by the androgen receptor. Mol Endocrinol $18,2633-48$.

[14] Hodgson, M.C., Shen, H.C., Hollenberg, A.N. and Balk, S.P. (2008) Structural basis for nuclear receptor corepressor recruitment by antagonist-liganded androgen receptor. Mol Cancer Ther 7, 3187-94.

[15] Rao, P.N. and Johnson, R.T. (1970) Mammalian cell fusion: studies on the regulation of DNA synthesis and mitosis. Nature 225, 159-64.

[16] Mutskov, V., Angelov, D. and Pashev, I. (1997) A preparative method for crosslinking proteins to DNA in nuclei by single-pulse UV laser irradiation. Photochem Photobiol $66,42-5$.

[17] Bolton, E.C., So, A.Y., Chaivorapol, C., Haqq, C.M., Li, H. and Yamamoto, K.R. (2007) Cell- and gene-specific regulation of primary target genes by the androgen receptor. Genes Dev 21, 2005-17.

[18] Shang, Y., Hu, X., DiRenzo, J., Lazar, M.A. and Brown, M. (2000) Cofactor dynamics and sufficiency in estrogen receptor-regulated transcription. Cell 103, 843-52.

[19] van Bokhoven, A., Varella-Garcia, M., Korch, C., Johannes, W.U., Smith, E.E., Miller, H.L., Nordeen, S.K., Miller, G.J. and Lucia, M.S. (2003) Molecular characterization of human prostate carcinoma cell lines. Prostate 57, 205-25.

[20] Bello, D., Webber, M.M., Kleinman, H.K., Wartinger, D.D. and Rhim, J.S. (1997) 
Androgen responsive adult human prostatic epithelial cell lines immortalized by human papillomavirus 18. Carcinogenesis 18, 1215-23.

[21] Berthon, P., Waller, A.S., Villette, J.M., Loridon, L., Cussenot, O. and Maitland, N.J. (1997) Androgens are not a direct requirement for the proliferation of human prostatic epithelium in vitro. Int J Cancer 73, 910-6.

[22] Ling, M.T., Chan, K.W. and Choo, C.K. (2001) Androgen induces differentiation of a human papillomavirus 16 E6/E7 immortalized prostate epithelial cell line. J Endocrinol 170, 287-96.

[23] Shang, Y., Myers, M. and Brown, M. (2002) Formation of the androgen receptor transcription complex. Mol Cell 9, 601-10.

[24] Velasco, A.M., Gillis, K.A., Li, Y., Brown, E.L., Sadler, T.M., Achilleos, M., Greenberger, L.M., Frost, P., Bai, W. and Zhang, Y. (2004) Identification and validation of novel androgen-regulated genes in prostate cancer. Endocrinology 145, 3913-24.

[25] Shen, R., Sumitomo, M., Dai, J., Hardy, D.O., Navarro, D., Usmani, B., Papandreou, C.N., Hersh, L.B., Shipp, M.A., Freedman, L.P. and Nanus, D.M. (2000) Identification and characterization of two androgen response regions in the human neutral endopeptidase gene. Mol Cell Endocrinol 170, 131-42.

[26] Bieberich, C.J., Fujita, K., He, W.W. and Jay, G. (1996) Prostate-specific and androgen-dependent expression of a novel homeobox gene. J Biol Chem 271, 3177982.

[27] Burd, C.J., Morey, L.M. and Knudsen, K.E. (2006) Androgen receptor corepressors and prostate cancer. Endocr Relat Cancer 13, 979-94.

[28] Prigent, C. and Dimitrov, S. (2003) Phosphorylation of serine 10 in histone H3, what for? J Cell Sci 116, 3677-85. 
[29] Solomon, M.J. and Varshavsky, A. (1985) Formaldehyde-mediated DNA-protein crosslinking: a probe for in vivo chromatin structures. Proc Natl Acad Sci U S A 82, 6470-4.

[30] Angelov, D., Khochbin, S. and Dimitrov, S. (1999) UV laser footprinting and proteinDNA crosslinking: application to chromatin. Methods Mol. Biology:Chromatin Protocols (Peter Becker ed.) Humana press 119, 481-495.

[31] Pashev, I.G., Dimitrov, S.I. and Angelov, D. (1991) Crosslinking proteins to nucleic acids by ultraviolet laser irradiation. Trends Biochem. Sci. 16, 323-326.

[32] Angelov, D., Khochbin, S. and Dimitrov, S. (1999) UV laser footprinting and proteinDNA crosslinking. Application to chromatin. Methods Mol Biol 119, 481-95.

[33] Nagaich, A.K., Walker, D.A., Wolford, R. and Hager, G.L. (2004) Rapid periodic binding and displacement of the glucocorticoid receptor during chromatin remodeling. Mol Cell 14, 163-74.

[34] Mutskov, V., Gerber, D., Angelov, D., Ausio, J., Workman, J. and Dimitrov, S. (1998) Persistent interactions of core histone tails with nucleosomal DNA following acetylation and transcription factor binding. Mol Cell Biol 18, 6293-304.

[35] Mutskov, V.J., Russanova, V.R., Dimitrov, S.I. and Pashev, I.G. (1996) Histones associated with non-nucleosomal rat ribosomal genes are acetylated while those bound to nucleosome-organized gene copies are not. J Biol Chem 271, 11852-7.

[36] Stefanovsky, V., Dimitrov, S.I., Russanova, V.R., Angelov, D. and Pashev, I.G. (1989) Laser-induced crosslinking of histones to DNA in chromatin and core particles: implications in studying histone-DNA interactions. Nucleic Acids Res 17, 10069-81.

[37] Stefanovsky, V., Dimitrov, S.I., Angelov, D. and Pashev, I.G. (1989) Interactions of acetylated histones with DNA as revealed by UV laser induced histone-DNA crosslinking. Biochem Biophys Res Commun 164, 304-10. 
[38] Angelov, D., Stefanovsky, V., Dimitrov, S.I., Russanova, V.R., Keskinova, E. and Pashev, I.G. (1988) Protein-DNA crosslinking in reconstituted nucleohistone, nuclei and whole cells by picosecond UV laser irradiation. Nucleic Acids Res 16, 4525-38.

[39] Angelov, D., Charra, M., Muller, C.W., Cadet, J. and Dimitrov, S. (2003) Solution study of the NF-kappaB p50-DNA complex by UV laser protein-DNA cross-linking. Photochem Photobiol 77, 592-6.

[40] Pashev, I.G., Dimitrov, S.I. and Angelov, D. (1991) Crosslinking proteins to nucleic acids by ultraviolet laser irradiation. Trends Biochem Sci 16, 323-6.

[41] Solomon, M.J., Larsen, P.L. and Varshavsky, A. (1988) Mapping protein-DNA interactions in vivo with formaldehyde: evidence that histone $\mathrm{H} 4$ is retained on a highly transcribed gene. Cell 53, 937-47.

[42] Martinez-Balbas, M.A., Dey, A., Rabindran, S.K., Ozato, K. and Wu, C. (1995) Displacement of sequence-specific transcription factors from mitotic chromatin. Cell 83, 29-38. 
Figure 1: Synchronization of RWPE-1-AR ${ }^{\text {tag }}$ cells using double thymidine block.

(A) Schematics of the RWPE-1-AR ${ }^{\text {tag }}$ synchronization protocol by double thymidine block. (B) Flow cytometry measurements of the percentage of cells at distinct phases of the cell cycle. Cells were harvested at the indicated time points after addition of thymidine. (C) Western blot analysis of the expressed AR at different phases of the cell cycle. Slight bands below the AR band are interpreted as degradation products. (D) Translocation of AR into the nucleus upon R1881 treatment in synchronized RWPE-1-AR ${ }^{\text {tag }}$ cells. Histograms show the percentage of AR-positive nuclei in the presence (+) and in the absence (-) of R1881.

Figure 2: Treatment with R1881 results in specific expression of AR target genes mRNA in synchronized RWPE-1-AR ${ }^{\text {tag }}$ cells at G1 phase of the cell cycle.

Total RNA was isolated from control cells and cells treated for 6 hours with R1881treated at the indicated phases of the cell cycle and used for RT-qPCR. CDK4 and GAPDH genes were used as negative controls. Means of 3 independent experiments are shown. Data represent the mean +/- SD from 3 independent experiments.

Figure 3: Cell cycle dependant expression of NCoR.

(A) NCoR mRNA expression in synchronized RWPE-1-AR ${ }^{\text {tag }}$ cells. One $\mu g$ of total RNA was reverse transcribed from each phases of the cell cycle. NCoR expression was quantified by RT-qPCR using specific primers. Data represent the mean +/- SD from 3 independent experiments. (B) Western blot analysis of the expression of NCoR protein in synchronized RWPE-1-AR ${ }^{\text {tag }}$ cells. The blot was revealed with an anti-NCoR specific antibody (upper panel). An anti-actin antibody was used for testing the equal loading (lower panel). (C) Dual-parameter FACS analysis of proliferating RWPE-1-AR ${ }^{\text {tag }}$ cells. One million exponentially growing cells were fixed and labelled either with an anti-phospho-histone $\mathrm{H} 3$ or an anti-NCoR antibody and propidium iodide as described in material and methods. As background control to position phases of the cell cycle, cells were labelled only with propidium iodide and FITC conjugated antibody.

Figure 4: $\mathrm{NCoR}$ is associated with ARE and surrounding chromatin regions only during the $\mathrm{S}$ phase.

ChIP were carried out on synchronized RWPE-1-AR ${ }^{\text {tag }}$ cells after crosslinking with 
formaldehyde using a specific anti-NCoR antibody. The data were normalized relative to DNA precipitated with a non-specific antibody (IgG). Means of 3 different experiments are presented.

Figure 5: Interaction of AR with chromatin following formaldehyde-induced crosslinking.

Control cells and cells treated with R1881 $\left(10^{-9} \mathrm{M}\right)$ for 6 hours were harvested at the indicated phases of the cell cycle and crosslinked with formaldehyde. ChIP were further performed using an anti-AR antibody. Precipitated DNA was amplified by using ARE specific primers and primers for DNA sequences located at $2 \mathrm{~kb}$ either upstream or downstream from the ARE for both NEP and CYR61 AR target genes. The data were normalized relative to DNA precipitated with non-specific antibody (IgG). The bottom two panels show the AR fold enrichment for non-AR target gene sequences (XBP and CDK4, negative controls). Data represent the mean +/- SD from 3 independent experiments. Note that the ordinate scales are different between the tested genes.

Figure 6: Interaction of AR with chromatin following UV laser induced crosslinking. Cells were harvested at the indicated phases of the cell cycle and irradiated with the UV laser as described in Materials and Methods. The crosslinked AR complexes were isolated using streptavidin-coated beads. Precipitated DNA was then amplified using ARE specific primers and primers for DNA sequences located at $2 \mathrm{~kb}$ either upstream downstream to the ARE for both NEP and CYR61 genes. Results are presented as fold enrichments relative to RWPE-1-pWR cells not expressing the tagged androgen receptor (pWR). Data represent the mean $+/-$ SD from 5 independent experiments.

Figure 7: Binding of RNA polymerase II to AR target genes in the chromatin.

The experiment was carried out as described in figure 6 except that RNA polymerase II-DNA complexes were recovered with a specific antibody against the enzyme. The fold enrichment for each gene was normalized relative to DNA precipitated with nonspecific antibody (IgG). Data represent the mean +/- SD from 3 independent experiments. 
Figure 8: Analysis of the interaction between NCoR and AR on the chromatin during the cell cycle.

Synchronized RWPE-1-AR ${ }^{\text {tag }}$ cells were treated with formaldehyde and the covalent NCoR-chromatin complexes were precipitated with anti-NCoR antibody. After elution, the complexes were re-immunoprecipitated with anti-AR antibodies. The data represent the fold enrichment relative to the control re-ChIP using the non-specific antibody combination IgG-IgG. AR-IgG and IgG-NCoR correspond to additional controls where antibodies against AR or NCoR were respectively replaced by control IgG. The sequential ChIP were performed by using the pooled material from two independent ChIP experiments. Note that ordinate scales are different between tested genes.

Figure 9: Knock-down of NCoR affects cell cycle dependent expression of AR target genes in synchronized RWPE-1-AR ${ }^{\text {tag }}$ cells.

(A): expression of NCoR mRNA and protein in cells treated with respectively shScrbl and shNCoR shRNA.

(B): Expression of AR target genes and control genes in synchronized RWPE-1-AR ${ }^{\text {tag }}$ cells expressing scramble shRNA or NCoR shRNA.

(C): Binding of AR to chromatin in genes in synchronized RWPE-1-AR ${ }^{\text {tag }}$ cells expressing scramble shRNA or NCoR shRNA. Binding was analysed following UV laser induced crosslinking similarly to experiments in figure 6 .

All data represent the mean $+/-$ SD from 3 independent experiments.

Figure 10: Overexpression of NCoR during the G1 phase abrogates expression of AR target genes.

(A): Expression of NCoR mRNA and protein in control cells and cells treated with doxycyclin.

(B): Expression of AR target genes and control genes in synchronized RWPE-1$\mathrm{AR}^{\text {tag }}$ control cells and cells overexpression NCoR following induction with doxycyclin.

Doxycycline was added to the medium to induce overexpression of NCoR and the cells were treated with R1881 for 6 hours. Cells at the indicated phase of the cell cycle were then processed for mRNA expression. Data represent the mean +/- SD 
from 3 independent experiments. 
A

\begin{tabular}{|c|c|c|}
\hline $\begin{array}{l}\text { Time } \\
\text { (hrs) }\end{array}$ & $\begin{array}{l}\text { Culture } \\
\text { conditions }\end{array}$ & $\begin{array}{l}\text { Time point } \\
\text { analysis }\end{array}$ \\
\hline $0 \Longrightarrow$ & Addition of excess thymidine & $\Longrightarrow \mathrm{TO}$ \\
\hline $16 \Longrightarrow$ & $\begin{array}{l}\text { Removal of thymidine \& } \\
\text { Addition of deoxycytidine }\end{array}$ & T1 \\
\hline $24=$ & $\begin{array}{l}\text { Removal of deoxycytidine \& } \\
\text { Addition of excess thymidine }\end{array}$ & $\Longrightarrow \mathrm{T} 2$ \\
\hline $49 \Longrightarrow$ & Removal of thymidine & $\Longrightarrow \mathrm{T} 3$ \\
\hline 55 & Normal growth medium & $\Longrightarrow \mathrm{T} 4$ \\
\hline 74 & & $\mathrm{~T} 5$ \\
\hline
\end{tabular}

C

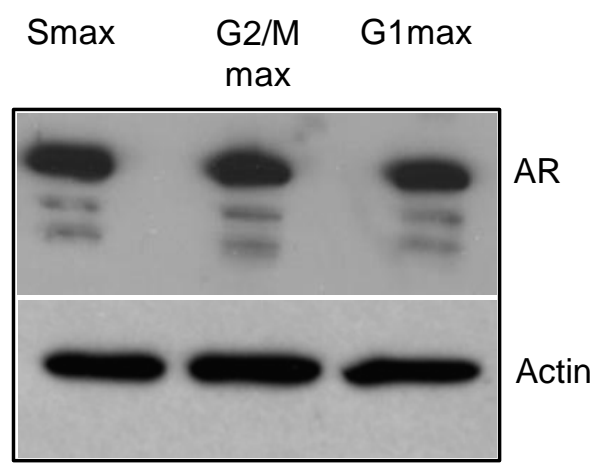

B
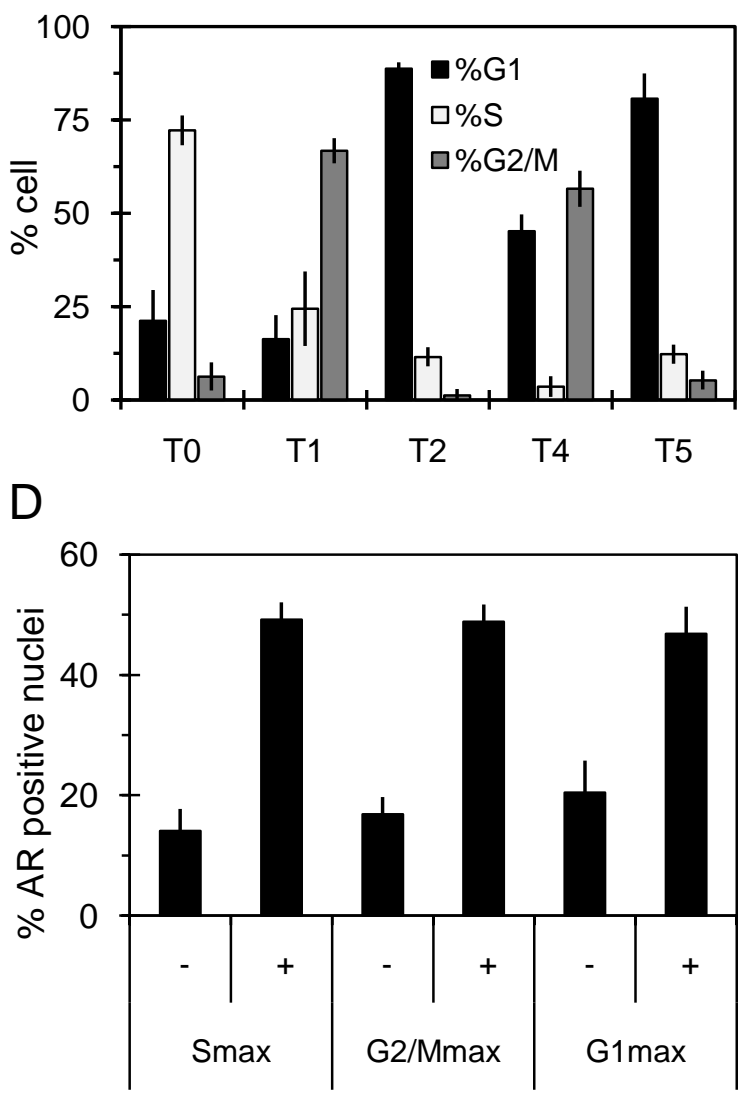

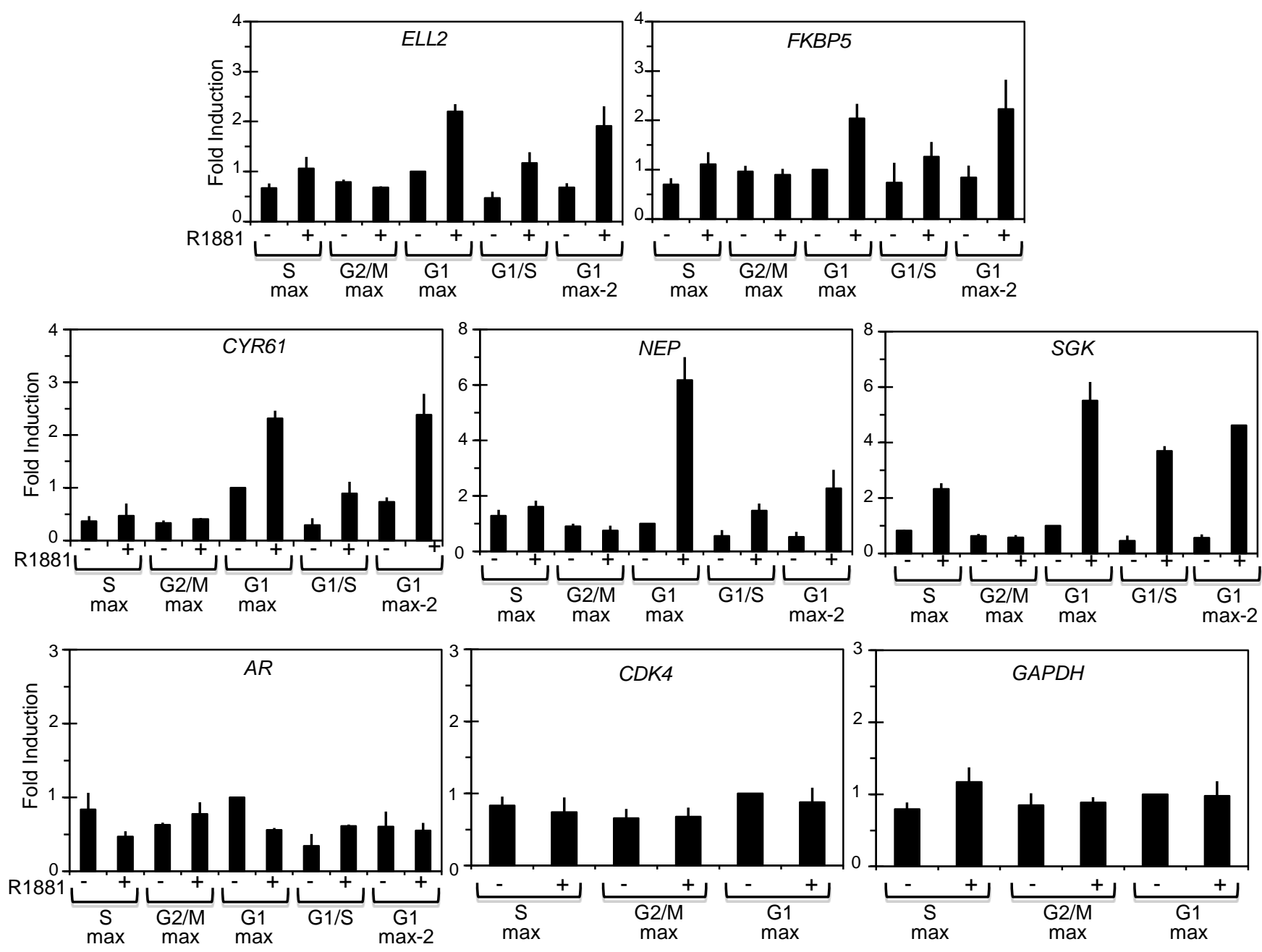

Figure 2 

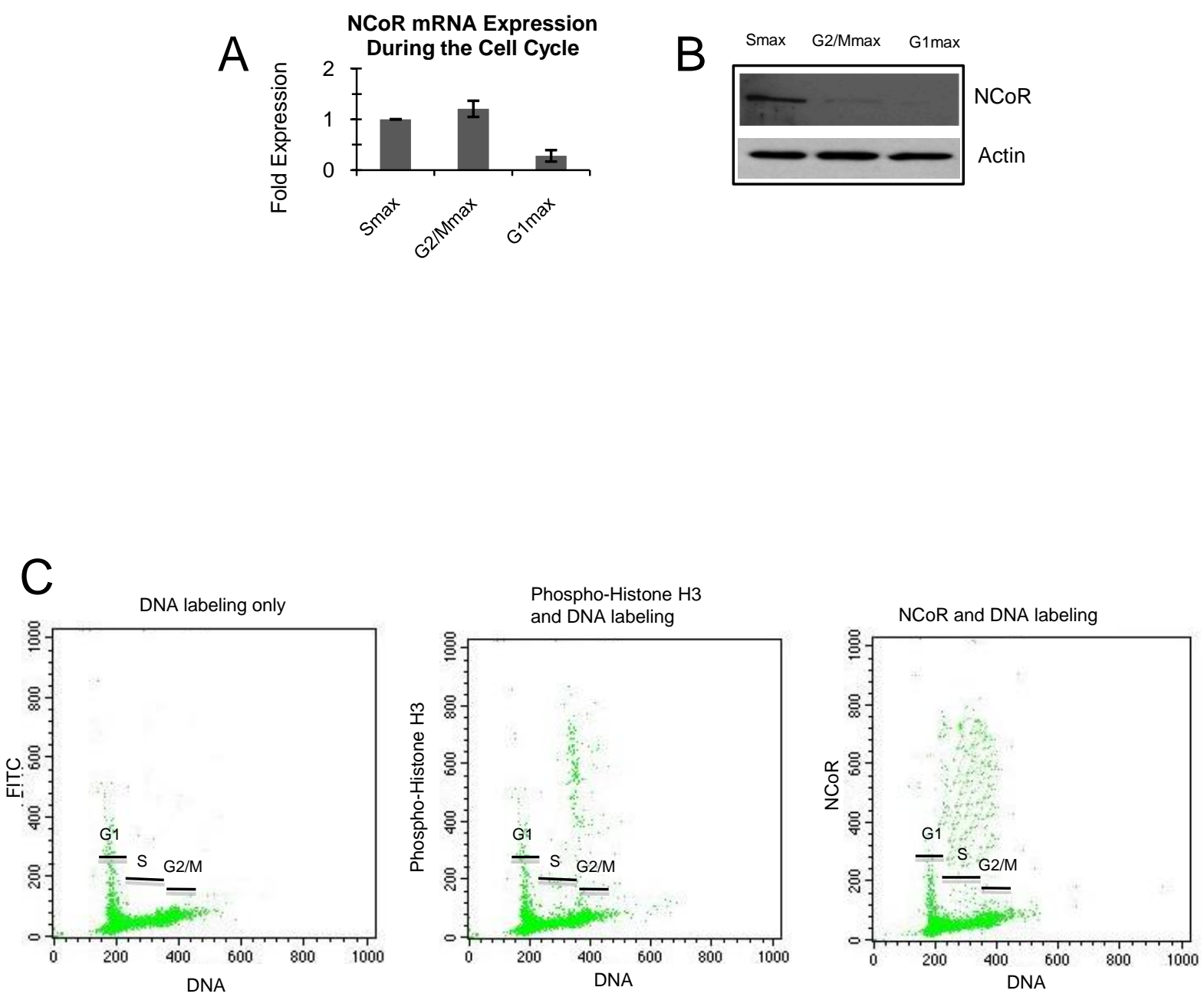

Figure 3 

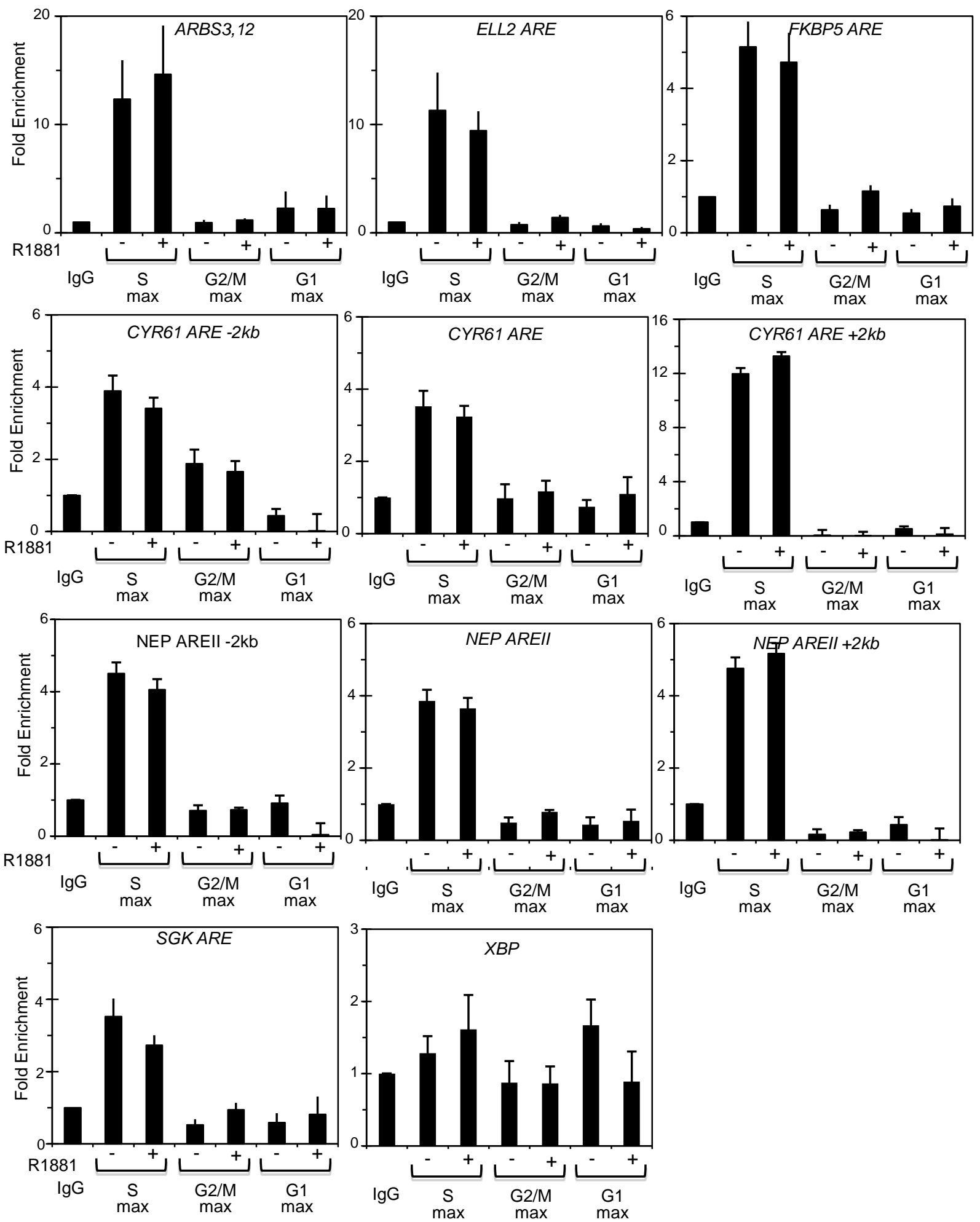

Figure 4 

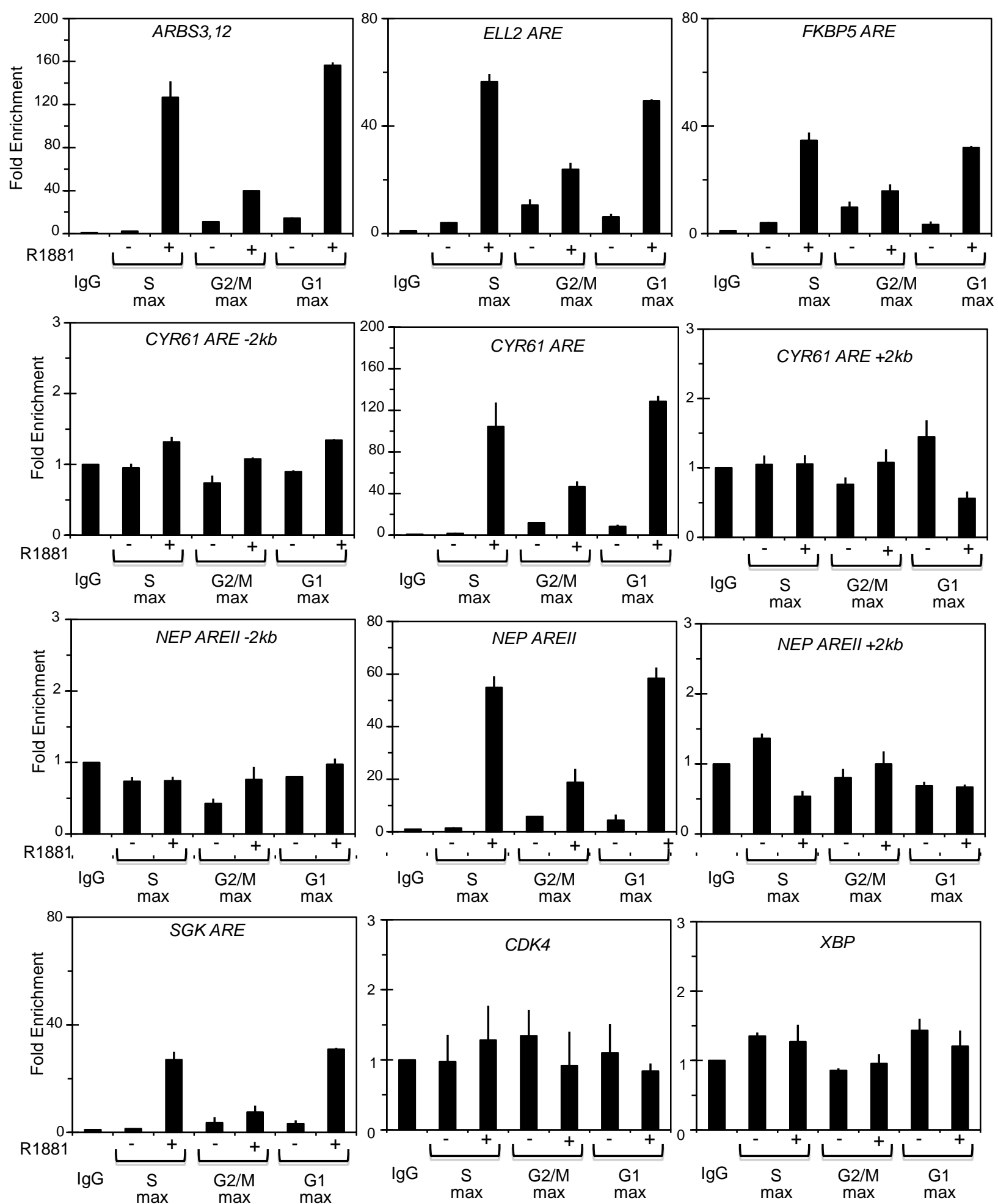

Figure 5 

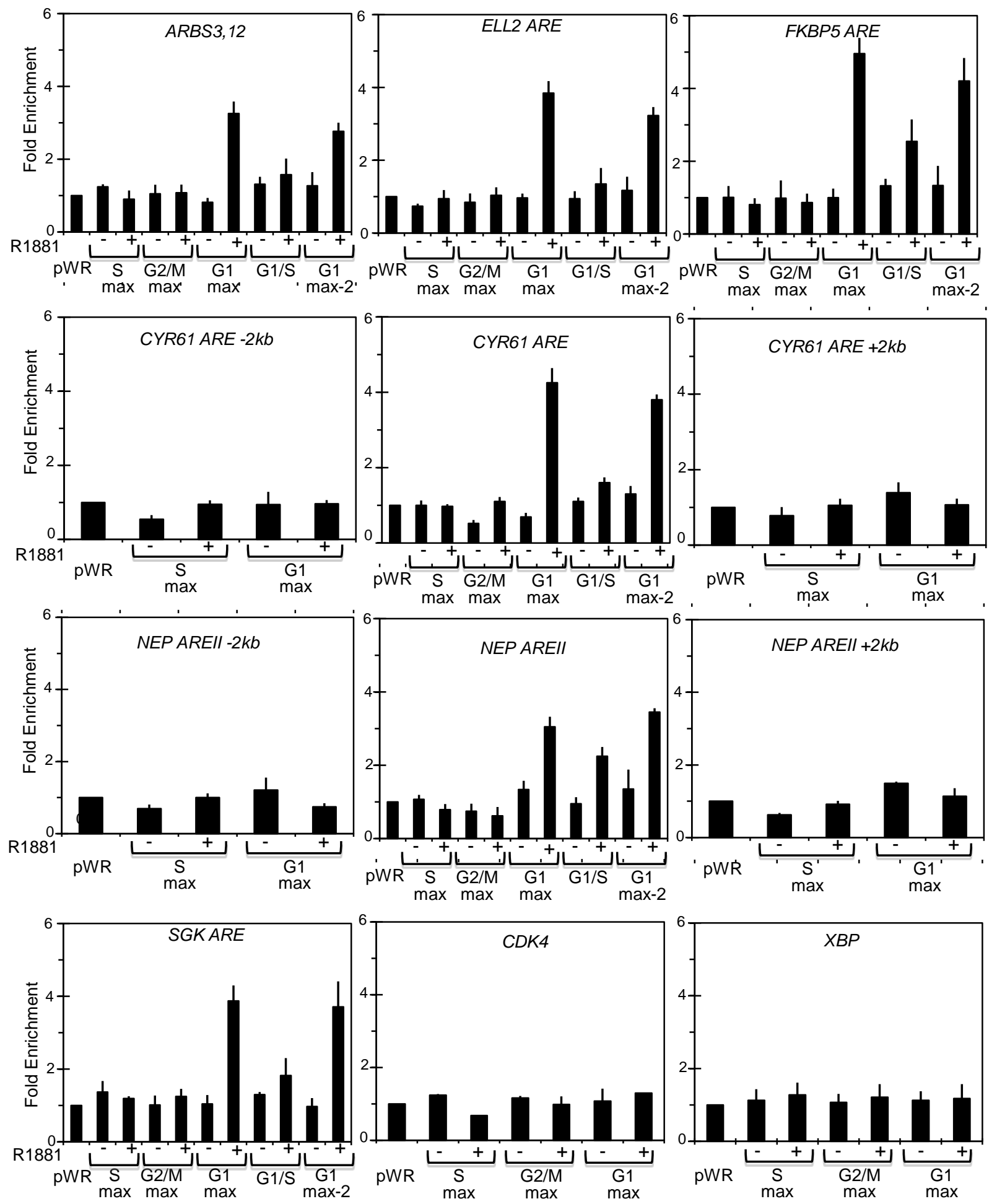

Figure 6 

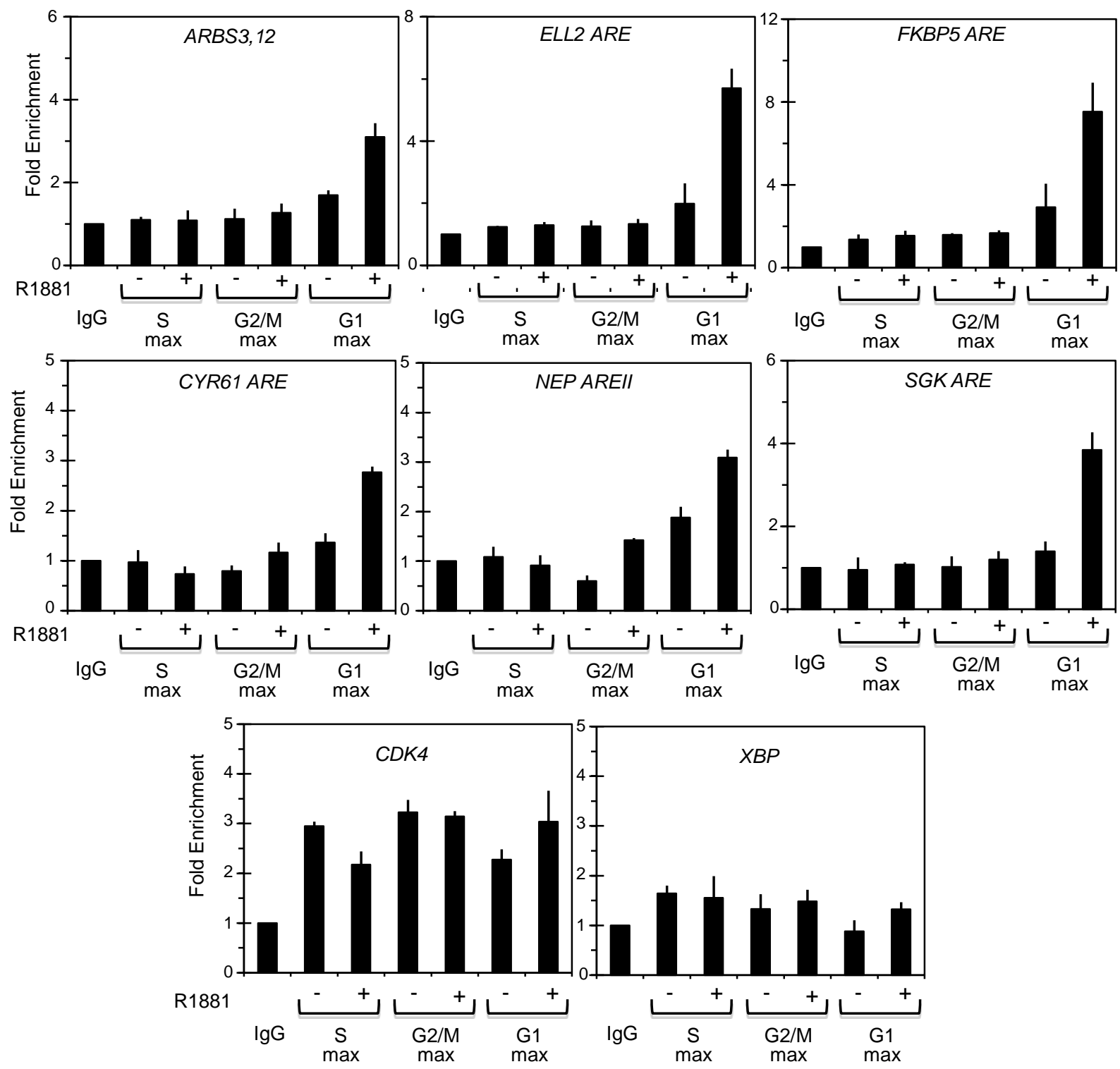

Figure 7 

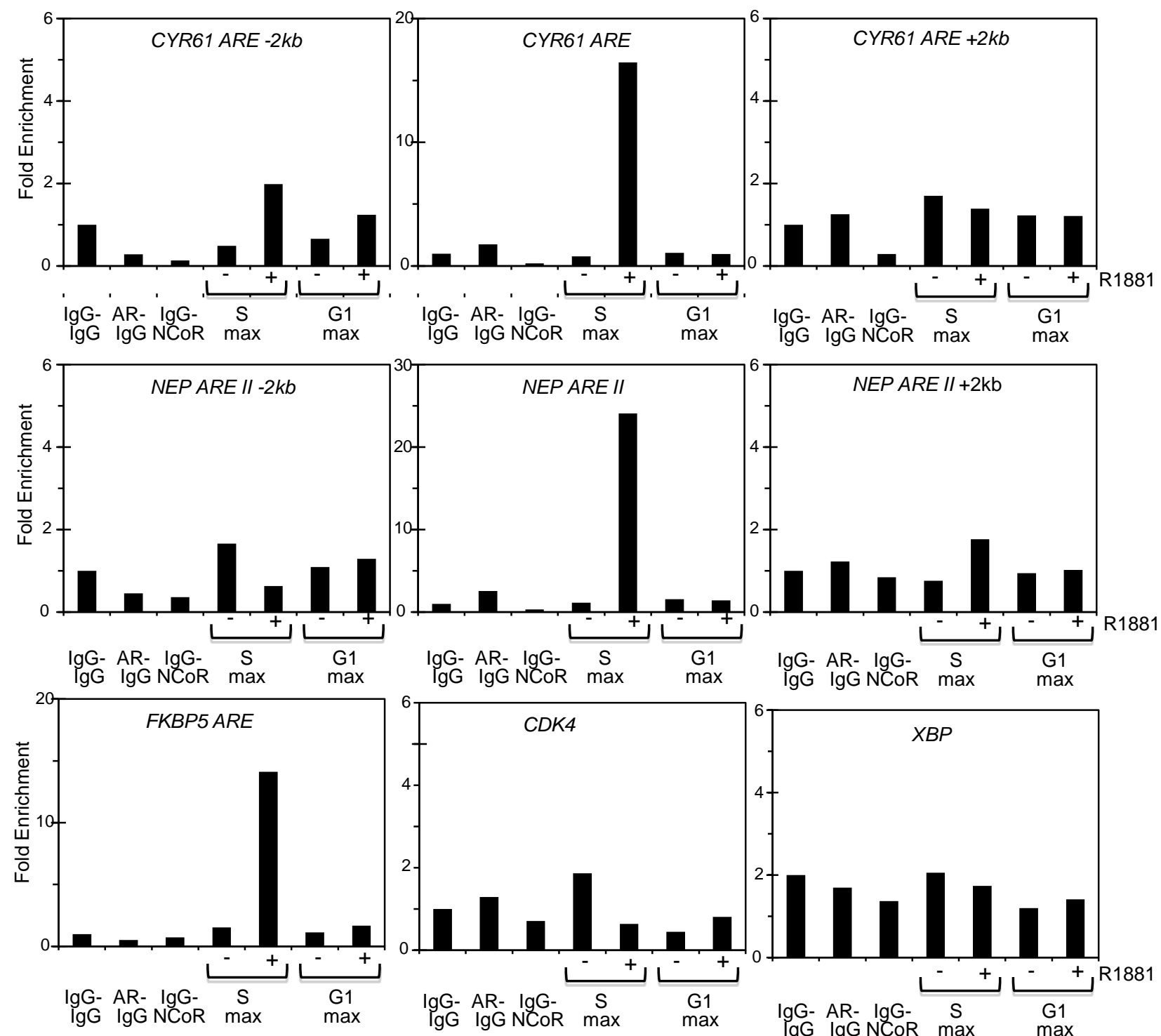

Figure 8 
A
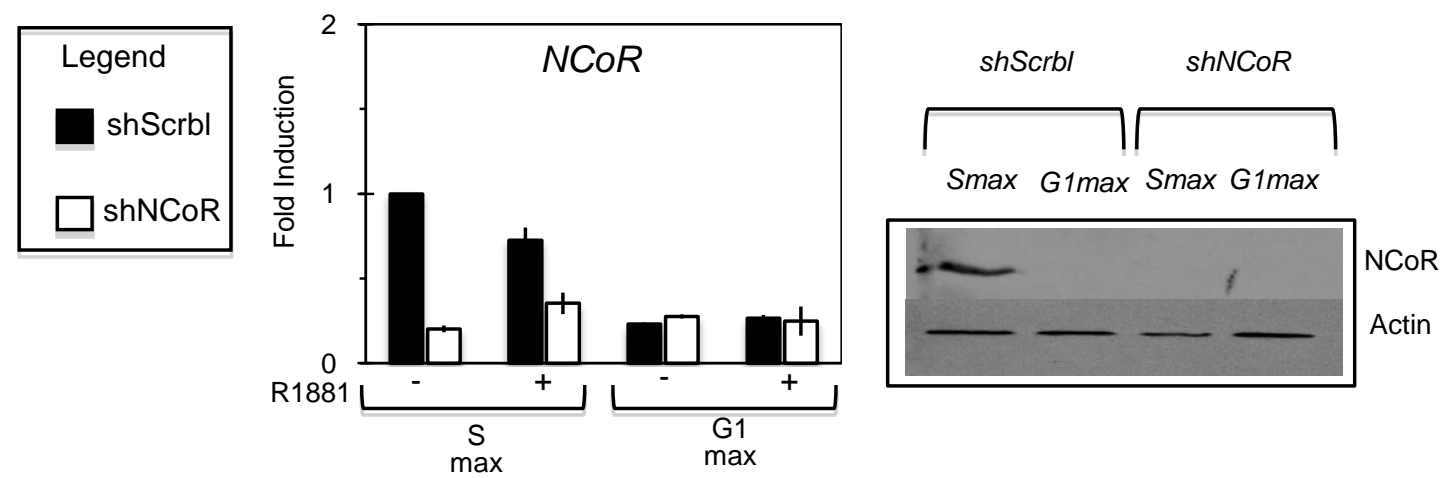

B
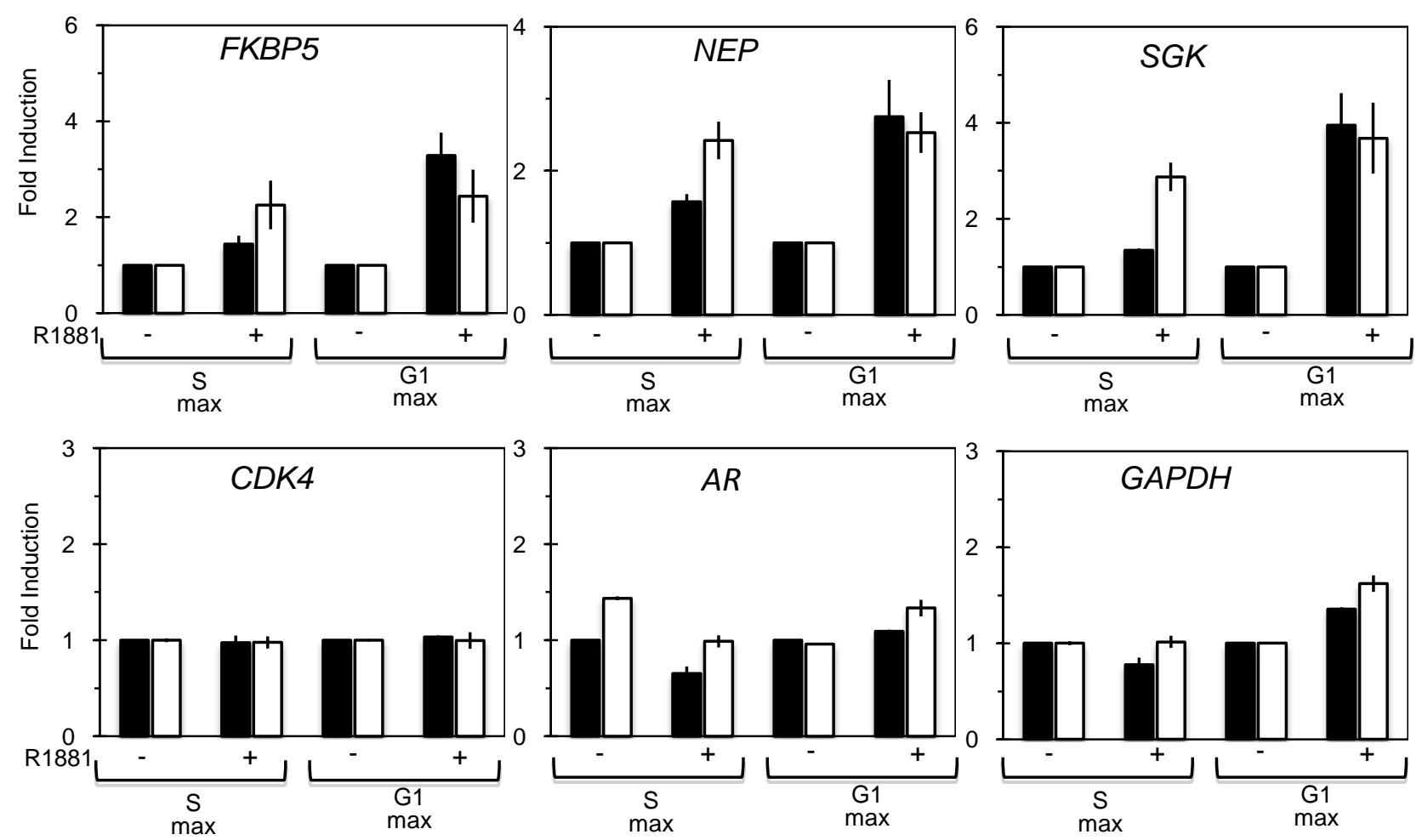

C
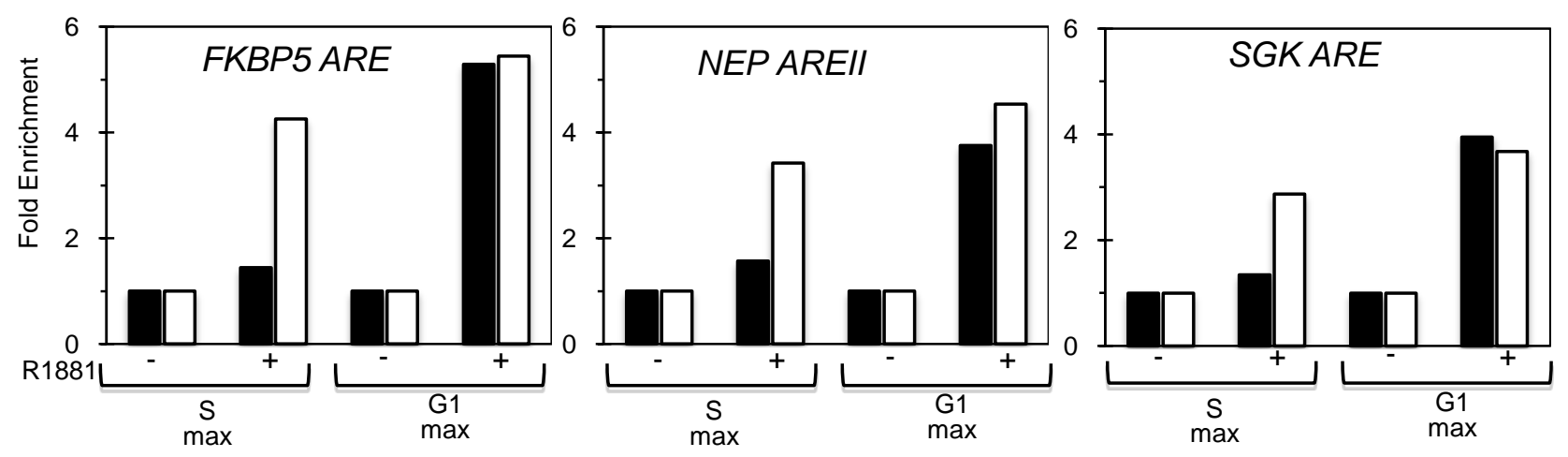

Figure 9 


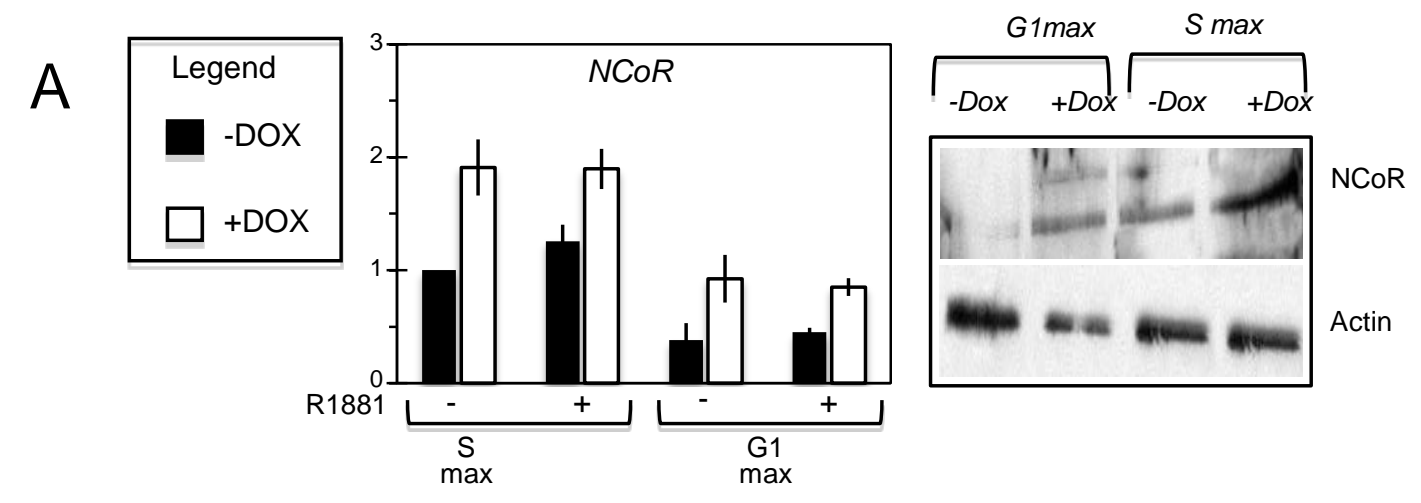

B
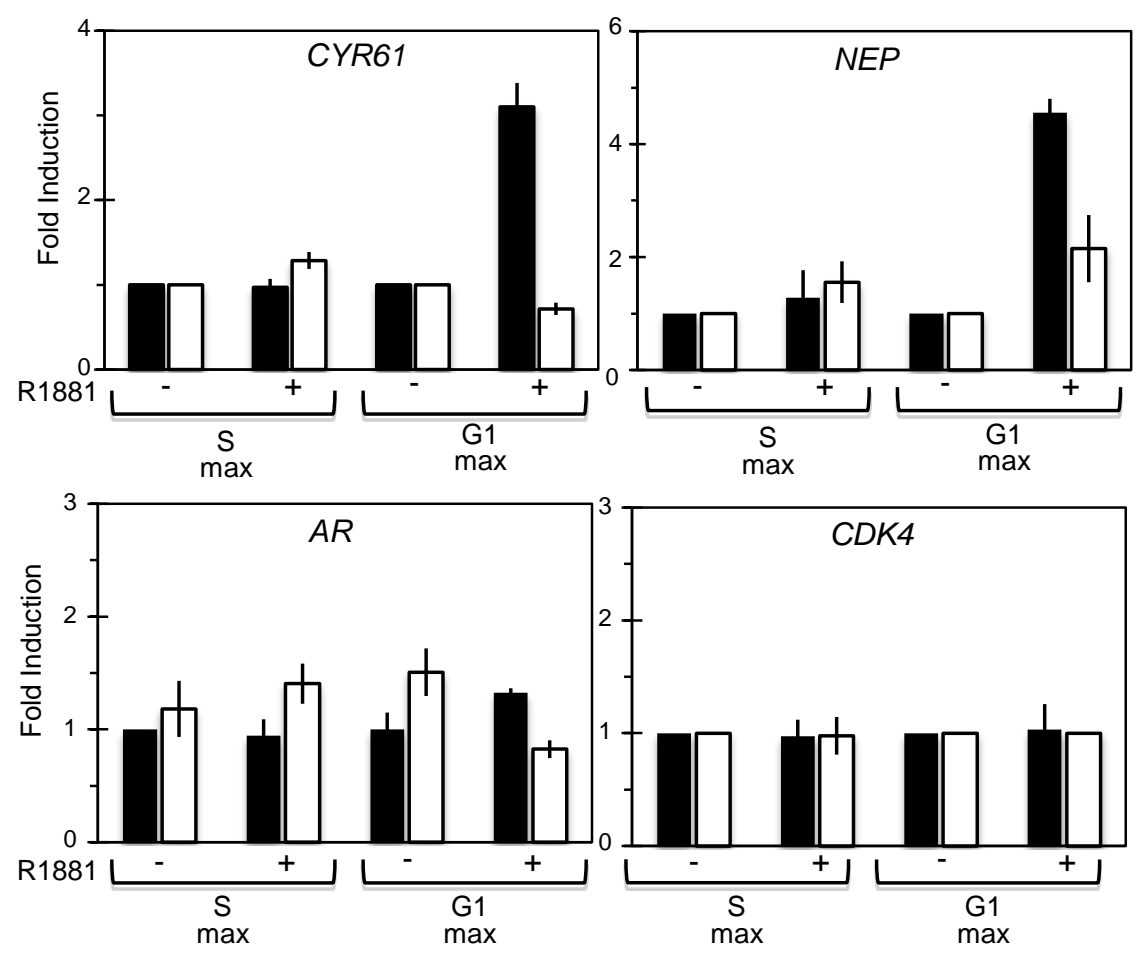

Figure 10 